\section{НОВАЯ НАУКА}

Международный центр

научного партнерства
NEW SCIENCE

International Center for Scientific Partnership

\title{
METHODS AND ANALYTICAL TOOLS IN THE ADVERTISING AND PUBLIC RELATIONS INDUSTRY
}

Textbook

Petrozavodsk

ICSP «New Science»

2021 
УДК 001.12

ББК 70

M54

Editor:

N. G. Kobus, $\mathrm{PhD}$ in psychology

Authors:

Mulina Natalya Alekseevna,

PhD, Associate Professor, Head of the Department of Advertising and Public Relations, Moscow International University, Moscow, Russia

Chvyakin Vladimir Alekseevich,

Professor of the Department of advertising and public relations in the media industry,

Moscow Polytechnic University, Moscow, Russia

Reviewers:

F. V. Sharoyko,

$\mathrm{PhD}$ in Economics, the Department of State and Municipal Administration, Institute of Social and Humanitarian Education, Moscow State Pedagogical University

A. V. Suhovilin,

Deputy General Director for Sales of MAER GROUP

\author{
Mulina, Natalya Alekseevna. \\ M54 METHODS AND ANALYTICAL TOOLS IN THE ADVERTISING AND \\ PUBLIC RELATIONS INDUSTRY : [textbook] / N. A. Mulina, V. A. Chvyakin /. - \\ Petrozavodsk : ICSP "New Science", 2021. - 99 c.
}

ISBN 978-5-00174-130-5

The tutorial contains materials on the use of analytics methods and tools in advertising and PR activities. The possibilities of complex use of analytical methods for an objective assessment of the economic efficiency of these types of activities, taking into account qualitative or quantitative indicators that can be processed using statistical tools, are shown. The textbook is addressed to undergraduate students studying the discipline "Methods and means of analytics in advertising and PR activities".

Recommended by the Academic Council (Senate) of ANOVO "MOSCOW INTERNATIONAL UNIVERSITY" for use in the educational process as a textbook for students in the field of training 42.03.01 Advertising and public relations of all forms of education, Protocol No. 9 of February 25, 2021.

УДК 001.12

ББК 70

ISBN 978-5-00174-130-5 


\section{CONTENT}

Introduction .

Section 1. Automated systems for analyzing and processing advertising and PR data 6

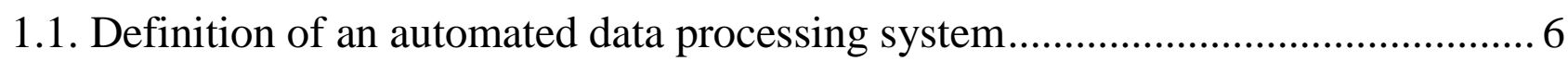

1.2. Automated data processing systems, their capabilities in solving advertising tasks...6

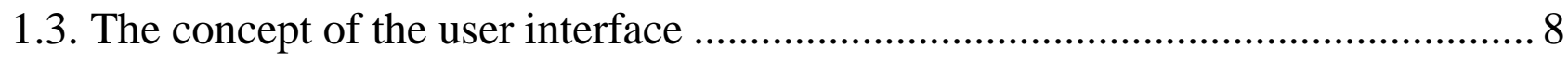

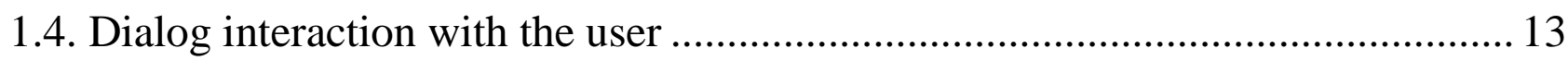

Section 2. Database management systems.......................................................................... 16

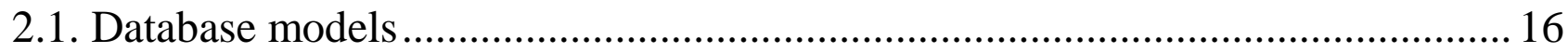

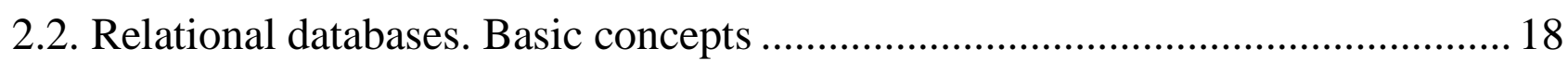

2.3. Database architecture. Functional architecture of automated data processing systems and dialog interaction with the user........................................................... 20

2.4. Modern approaches to the collection, storage and use of information in the

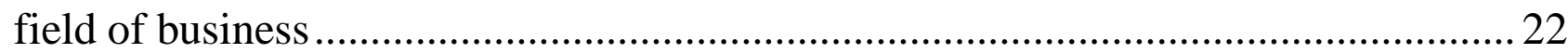

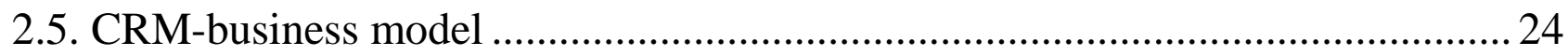

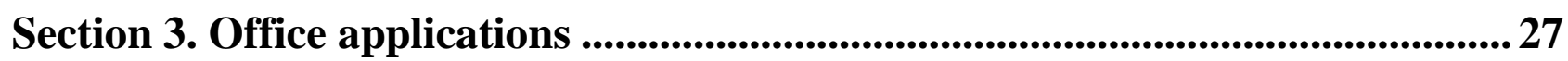

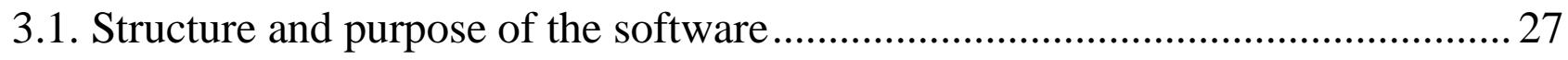

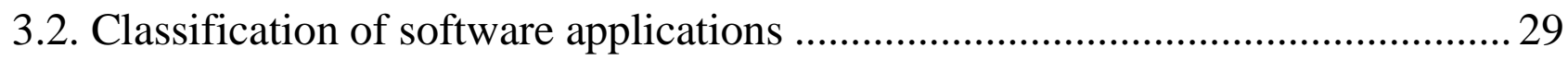

3.3. Stages of database design in Microsoft Access. Types of inter-table relationships

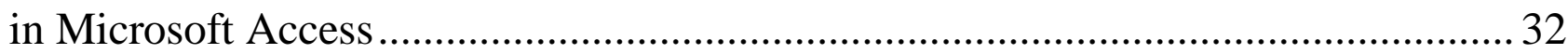

3.4. Text editor, databases, spreadsheet, presentation and publication preparation

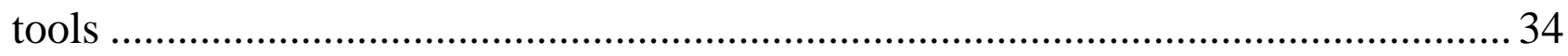

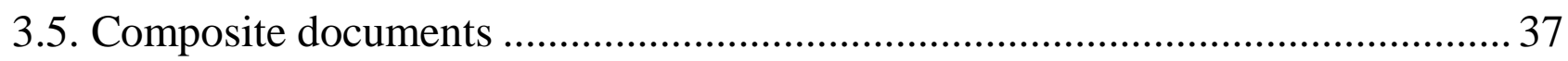

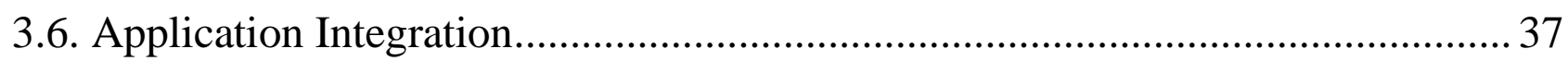

Section 4. Analysis of advertising research software features ................................. 42

4.1. Software for collecting advertising information ............................................ 42

4.2. Software for analyzing advertising information. Software for media research and

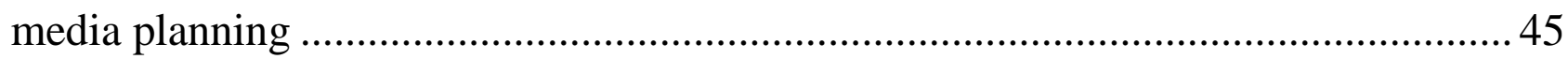

4.3. Application of the SPSS statistical Analysis package in Advertising Research.. 47 Section 5. Evaluating the effectiveness of advertising in mailing lists and teleconferences

5.1. Banner-the main advertising medium. The effectiveness of the banner. Payment

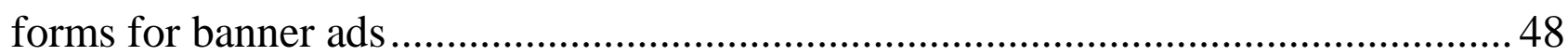

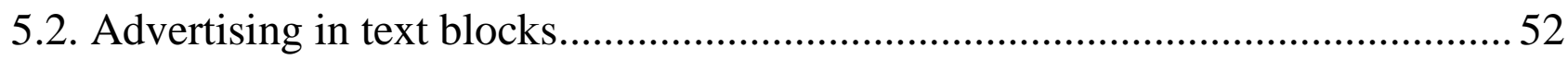

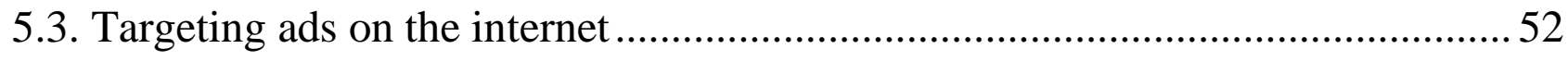


Section 6. Analysis of the effectiveness of online advertising..................................55

6.1. Levels of evaluation of the effectiveness of Online advertising ......................... 55

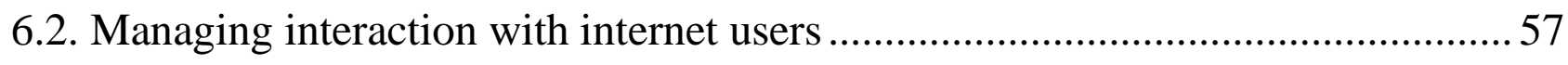

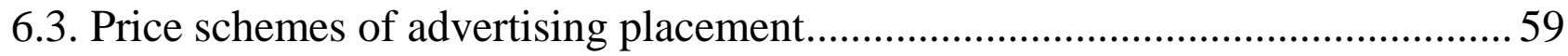

6.4. Evaluating the effectiveness of an advertising campaign ..................................... 63

Section 7. Analysis of the economic efficiency of an advertising campaign ........ 68 7.1. Analysis of the relationship between the result obtained from advertising and the invested funds for its implementation over a certain period of time .......................... 68

7.2. Analysis of the impact of advertising on the change in turnover......................... 71

Section 8. Quantitative and qualitative assessments of the effectiveness of advertising and PR ............................................................................................ 74

8.1. Tracking an advertising campaign taking into account financial costs ............... 74

8.2. Preliminary or control study of the advertising strategy .................................. 76

8.3. The dependence of advertising effectiveness on the survey objectives and the sample size of respondents. The dependence of the effectiveness of advertising on the measurement tools and the probability of making a purchase ................................... 78

Section 9. The process of controlling an advertising campaign ............................. 83

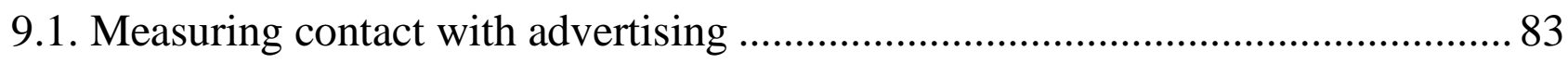

9.2. Studying the effects of brand communication and positioning........................... 84

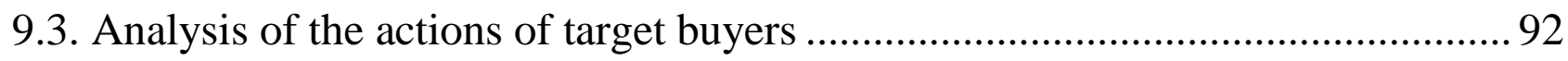

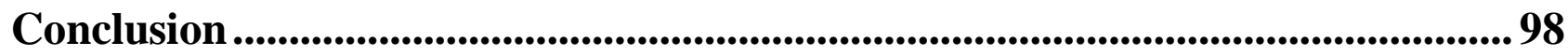

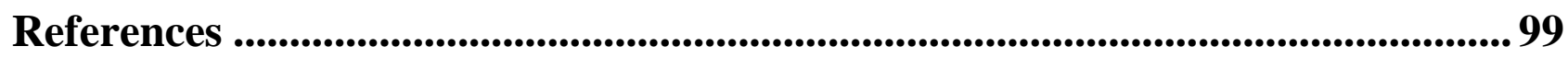




\section{Introduction}

The main goal of studying the discipline "Methods and means of analytics in advertising and PR activities" should include mastering information and analytical technologies for using them in their professional activities. In connection with this orientation of training, it is necessary to pay special attention to the following areas of student training:

- study of applied issues of information technologies, the possibilities of their use in the process of advertising activities;

- getting the basics of knowledge about database technologies (DBMS). Knowledge of the main database architectures, the ability to use their capabilities in the preparation, development and implementation of advertising events;

- study of the theoretical foundations and acquisition of practical skills in studying the potential advertising audience, processing the results of audience research using modern statistical software products;

- review of applications used in advertising research (SPSS).

Mastering the discipline "Methods and tools of analytics in advertising and PR activities" contributes to the formation of such competencies as the ability to participate in the planning, preparation and conduct of communication campaigns and events and the ability to master the skills of writing analytical reports, reviews and forecasts.

The discipline "Methods and means of analytics in advertising and PR activities" is directly related to the need for marketing research. Media monitoring, media monitoring, and press clipping are important components of PR analysis and any serious marketing research. Qualified monitoring is not just a review of the media, but a complex complex work. Media monitoring involves accurately determining the position of business in the mass consciousness or in the professional environment, the activity of the main competitors, existing trends and dependencies in the business, industrial, financial and political life of society. It is not limited to press monitoring and press clipping - it is only the basis for serious analytical work necessary to bring disparate facts to a common understanding of the current situation and prospects.

The material of the textbook for the study of the discipline "Methods and means of analytics in advertising and PR activities" contributes to the formation of students ' scientific worldview, which is important in relation to the conditions of their independent professional activity in the future. 


\section{SECTION 1. \\ AUTOMATED SYSTEMS FOR ANALYZING AND PROCESSING ADVERTISING AND PR DATA \\ 1.1. Definition of an automated data processing system}

Data is information about facts and events in a specific subject area, obtained by measurement, observation, logical or arithmetic operations, presented in a form suitable for permanent storage, transmission and automated processing. Automated data processing system (ASOD) [electronic data processing system] - a data processing system based on the use of electronic computers (computers) in contrast to systems where data processing is manual. There are two possible principles for organizing such processing. In the first case, information is collected and processed specifically for each task, in the second - for solving various tasks, along with variable, task-specific information, general reference (conditionally constant) data is used. In the latter case, the system is called integrated.

The main function of the data processing system is the implementation of typical data processing operations, namely:

- collecting, registering and transferring it to machine media;

- transfer of information to the places of its storage and processing;

- entering information into the computer;

- maintenance of an in-machine information base;

- processing of information on a computer (accumulation, grouping, sorting, correction, arithmetic and logical operations) to solve the functional problems of the object management system;

- output of information in the form of tables, charts, reports;

- management (administration) of the computing process (planning, accounting, control, analysis of the progress of calculations) in local and global computer networks.

\subsection{Automated data processing systems, their capabilities in solving advertising tasks}

ASODS are used in planning and management (automated control systems automated control systems), in scientific research (automated systems for collecting and processing experimental data and test automation systems), in librarianship and information services, in design (CAD-computer-aided design and design work systems) and other areas. 


\section{METHODS AND ANALYTICAL TOOLS IN THE ADVERTISING AND PUBLIC RELATIONS INDUSTRY}

Automated control system (ACS) [automated, automated control system (ACS), computerized control system, management information system (MIS)] - a control system that uses modern automatic data processing tools and economic and mathematical methods to solve the main tasks of managing production and economic activities. This is a human-machine system: in it, a number of operations and actions are transferred for execution to machines and other devices (especially this applies to the so-called routine, repetitive, standard calculation operations), but the main decision is always left to the person. This is how automated control systems differ from automatic systems, that is, such technical devices that operate independently, according to the program set for them, without human intervention.

According to the types of control processes, automated control systems are divided into two classes: automated organizational management systems and automated process control systems (the latter are often automatic, the former cannot be in principle).

In the publications of recent years, a similar term ASOI (automated information processing systems) is used, which means systems that are not necessarily related to the management of certain objects (enterprises, organizations, technological processes).

ASMS are characterized by functional classes of tasks of the corresponding enterprises and organizations in a specific subject area. These include the tasks of accounting, tax activities, marketing, advertising, etc.

Depending on the class of technological operations implemented, the solutions of applied problems in the ASOD are text editors, spreadsheets (table processors), database management systems, multimedia systems (graphic editors, audio and video processing tools, computer graphics and animation programs), etc.

The general structure of the ASOD consists of information (documentation, classification and coding methods, methods of creating a database), technical (technical means), mathematical (methods and algorithms), software, organizational (interaction of personnel with each other and with technical means), linguistic (a set of language tools used at various stages of development) and legal support (legal norms).

A database (DB) is a collection of specially structured and interconnected data related to a specific subject area or application task, intended for storage and delivery to users upon their requests. Examples of a database can be the phone. a book, a book catalog in the bible, a legal reference system, etc. 
The database management system (DBMS) is a set of software and linguistic SR-V, capable of maintaining the database.

Database management: - database design; - data entry; - data editing (updating, adding, deleting data); - search for data based on user requests; - analyze and print data using reports, etc.

Depending on the organization method (model):

- hierarchical (an ordered set of trees, the vertices are connected by vertical relations of subordination of the lower level to the higher one).

- network (allows any object to be connected to any object, that is, there are horizontal connections in it).

- object-oriented (provides access to various data sources. They are used in modeling, multimedia, telecommunications, and publishing).

- relational (a set of two-dimensional tables that characterize a certain subject area, information that is stored in the form of an ordered set of records - table rows).

According to the method of organization and technology of data processing:

- centralized (traditional database architecture, in which all the data necessary for the work of specialists is placed on a central computer).

- distributed (stored on different computers)

According to the method of data access:

- local

- with remote (network) access (file-server (shared files are stored) and clientserver (computers are connected to a local network with the server).

\subsection{The concept of the user interface}

The main requirement for the user interface of commercial DBAs is its friendliness (friendliness), which means providing a convenient and natural way for the user to communicate with the DBAS. The degree of such friendliness depends on the orientation to a particular market segment.

The following methods increase the user-friendliness of the user interface:

- natural names of commands that are similar to similar names in other databases (for example, it is advisable to call search commands "find" "search", etc. output commands - "print", etc.);

- the presence of a developed system of hints (help);

- convenient procedure for issuing information.

An interface is a system of rules and tools that governs and ensures the interaction of several processes or objects. 
The User Interface (UI) is a system of rules and tools that governs and ensures the interaction of the program with the user. The concept of a user interface (PI) includes not only, and not even so much, a picture on the screen - three-dimensional, animated, or simply made in a fashionable design, but the ways in which the user interacts with the system.

A user interface (UI) is a type of interface in which one side is represented by a person (user), and the other side is represented by a machine/device. It is a set of tools and methods by which the user interacts with various, most often complex, machines, devices and equipment.

Very often the term is used in relation to computer programs, but it can mean a set of tools, methods and rules of interaction of any system controlled by a person.

The set of tools and methods of the user interface means:

\section{Tools:}

- output of information from the device to the user - the entire available range of effects on the human body (visual, auditory, tactile, olfactory, etc.) - screens (displays, projectors) and light bulbs, speakers, buzzers and sirens, vibration motors, etc.;

- input of information/commands by the user into the device-a variety of various devices for monitoring the state of a person - buttons, switches, potentiometers, position and motion sensors, servos, gestures with the face and hands, even eating the user's brain activity.

According to the presence of various input tools, interfaces are divided into types - gesture, voice, brain, etc., mixed options are possible. These tools should be necessary and sufficient, be convenient and practical, arranged and arranged reasonably and clearly, correspond to human physiology, should not lead to negative consequences for the user's body (all this is included in the concept of ergonomics).

\section{Methods:}

- a set of rules laid down by the device developer, according to which a set of user actions should lead to the necessary reaction of the device and the execution of the required task - the so-called logical interface.

These rules should be clear enough to understand, natural and easy to remember (all this is included in the concept of usability).

The increase in the device (with equal functionality) of the I / O means makes it easier to build control methods and simplify the rules of use, but it leads to the complexity of the user's perception of information - the interface becomes overloaded. And vice versa-reducing the display and control means leads to more 
complex control rules - each element carries too many functions. Therefore, interface designers try to make a compromise decision between these two extremes in each individual case.

The conceptual design of the interface should be based on the idea of the interface environment. While working with the system, the user is immersed in the interface environment. The word environment is used as a designation of the "signal - action" combination typical for human behavior in various environments.

This idea belongs to Gibson, who argues that perception is based on motivation in the sense that if we want to eat, we see only edible things, and if we are tired, then only pieces of furniture intended for recreation. That is, a person does not just see, but interrogates the environment, guided by various motives. In turn, the environment gives a person different signals. Along with the responses to its requests, there are priority (or always requested) signals related to physical danger. Based on the received signals, a person performs various actions.

The user interface combines all the elements and components of the program that can influence the user's interaction with the software. These elements include:

- a set of user tasks that the user solves with the help of the system;

- a metaphor used by the system (for example, the desktop in MS Windows);

- system controls;

- navigation between system blocks;

- visual (and not only) design of the program screens;

- information display tools, displayed information, and formats;

- data entry devices and technologies;

- dialogs, interactions, and transactions between the user and the computer. User Feedback;

- support for decision-making in a specific subject area;

- the procedure for using the program and its documentation.

The user interface is a set of tools and rules for human-computer interaction. Human-computer interaction today is based on an object-oriented graphical interface, in which: all objects are represented as icons; objects are operated in windows; the main element of software control is the menu; the main element of hardware control is various manipulators.

The user's information space is information resources (files with programs, documents, Web sites, photos, video clips, etc.) that are available to the user when working on a computer.

The human-computer interface includes two main components: 
- a dialog process that links background processes into a single system;

- a set of I / O processes that provide a physical connection between the user and the dialog process.

As in communication between people, the dialogue with the computer must meet certain rules. The development of the dialogue consists in bringing these rules into line with the psychological needs and ideas of the person.

The user interface is a representation of the software and hardware that enable the user to interact with the computer. The basis of such interaction is dialogues. In this case, a dialogue is understood as a regulated exchange of information between a person and a computer, carried out in real time and aimed at jointly solving a specific task. Each dialog consists of separate input and output processes that physically connect the user and the computer.

The exchange of information is carried out by the transmission of a message.

Basically, the user generates the following types of messages:

- request for information;

- request for help;

- request an operation or function;

- entering or changing information.

In response, the user receives hints or help; informational messages that require a response; orders that require action; error messages and other information.

Interface types:

There are two types of user interfaces:

1) procedure-oriented:

- primitive;

- menu;

- with free navigation;

2) object-oriented:

- direct manipulation.

The procedure-oriented interface uses a traditional model of user interaction based on the concepts of "procedure" and "operation". Within this model, the software provides the user with the ability to perform certain actions for which the user determines the correspondence of the data and the result of which is to obtain the desired result.

Procedure-oriented interfaces:

1) provides the user with the functions necessary to complete the tasks;

2) the focus is on the tasks; 


\section{METHODS AND ANALYTICAL TOOLS IN THE ADVERTISING AND PUBLIC RELATIONS INDUSTRY}

3) icons represent applications, windows, or operations;

4) the contents of folders and directories are reflected using a list table.

Object-oriented interfaces use a model of user interaction that focuses on the manipulation of objects subject area. Within this model, the user is given the opportunity to directly interact with each object and initiate operations in which several objects interact. The user's task is formulated as a purposeful change of some object. An object is understood in the broadest sense of the word - a database model, system, etc.

Object-oriented interfaces:

1) provides the user with the ability to interact with objects;

2) the emphasis is on input data and results;

3) pictograms represent objects;

4) folders and directories are visual containers of objects.

A primitive interface is an interface that organizes user interaction and is used in console mode. The only deviation from the sequential process that is provided by the data is the organization of a loop for processing multiple data sets.

The menu interface. In contrast to the primitive interface, it allows the user to select an operation from a special list displayed by the program. These interfaces assume the implementation of a variety of work scenarios, the sequence of actions in which is determined by the users. The tree-like organization of the menu assumes a strictly limited implementation. In this case, there are two options for organizing the menu:

- each menu window takes up the entire screen;

- there are several multi-level menus (Windows) on the screen at the same time.

In conditions of limited navigation, regardless of the implementation option, finding an item in more than two-level menus is quite a challenge.

Interface with free navigation (graphical interface). Supports the concept of interactive interaction with the software, visual feedback from the user and the ability to directly manipulate the object (buttons, indicators, status bars). In contrast to the Menu interface, the interface with free navigation provides the ability to perform any operations allowed in a particular state, which can be accessed through various interface components ("hot" keys, etc.). The interface with free navigation is implemented using event-based programming, which involves the use of visual development tools (via messages). 
The object-oriented interface assumes that user interaction is carried out by selecting and moving the icons of the corresponding object-oriented area.

There are single-document (SDI) and multi-document (MDI) interfaces.

\subsection{Dialog interaction with the user}

By now, new automated services are gradually replacing the natural telephone conversation between people. Traditional telephone communication has developed into a complex for the transmission of voice, sound, image, video, text and information through landline and mobile applications.

Intelligent dialog systems are a system of voice self-service of customers (providing services and services via a telephone communication channel via voice). Speech dialog systems are "computer systems that users interact with in turn". Conversational dialog systems are a speech (voice) user interface. In this case, the interface refers to the elements and components of the program that can influence the user's interaction with the software. The basis of such interaction is dialogues.

Dialog (interactive) mode - a method of interaction between a user or operator with a computer, in which there is a direct and two-way exchange of information, commands or instructions between a person and a computer. The dialog mode implies a speed of data processing that does not affect the technology of user actions. Each dialogue consists of separate processes, I/o, which is physically provide a relationship between the user and the computer. The exchange of information is carried out by the transmission of a message.

The effectiveness of the use of dialogue systems. On the one hand, conversational dialog systems have a number of advantages: naturalness, efficiency, semantic accuracy of input, freeing the user's hands and vision. On the other hand, there are a number of limitations: the user's language must be accessible and understandable to the system; the user does not know about all the features of the system. In the process of interacting with a computer, the user needs to quickly capture information, since speech is of a fleeting nature of perception. The effectiveness of natural speech recognition is far from perfect. This is due to the fact that the speech signal has a complex variable structure: contains, in addition to words known to the system, unfamiliar words, fragments of speech, acoustic noise, the same word can have different meanings.

The information dialog of the system "Man-Man". Modern telephone networks provide users with ubiquitous access to multi-view information and communication services. 


\section{METHODS AND ANALYTICAL TOOLS IN THE ADVERTISING AND PUBLIC RELATIONS INDUSTRY}

These systems can be divided into two main classes: automated services (machine+person) and services with the help of operator centers (call centers) (person+person).

In the case of call centers, the client communicates with the operator, who in turn interacts with the necessary information systems through a PC and application programs. The hardware can be implemented using telecommunications devices such as telephone exchanges, computer telephony boards, VoIP gateways, or on the basis of standard computer systems. Currently, a call center, or contact center, is the traditional way to provide information over the phone.

The specialized software of the contact center solves a number of tasks: performs interactive voice interaction between the operator and the subscriber; processes, records and analyzes calls received through various communication channels; analyzes and evaluates the quality of operators work (quality monitoring); routes incoming calls to the most qualified operator, plans the logic of the contact center and improves its efficiency.

When providing standard information, contact centers are not effective enough, so information dialog systems "man-machine" are created.

In this case, the subscriber will not have to wait for a response and process his request. In the case of automated services, the subscriber communicates with the system directly.

The information dialog of the system "Man-Machine" or a system of voice self-service.

To ensure the comfortable life of customers, new services of automated speech interaction are being created, which carry out dialogues, interaction and transactions between the user and the computer, for the transfer of information. The system of voice self-service of subscribers is an alternative for contact centers to provide reference information.

Automated telephone self-service systems are designed to provide services similar to computer systems, but through a telephone communication channel. The automatic customer service service significantly simplifies the receipt of reference information, reduces the waiting time and increases the company's working hours, and significantly reduces the cost of providing information to subscribers. The main advantage of automated systems is user friendliness - it eliminates the need to wade through the complex and confusing mazes of the menu.

The most advanced automated means of human-machine dialog interaction have the following characteristics: contain a dictionary of several thousand words; 
recognize spontaneous arbitrary speech; process the user's speech input data; manage the dialog; form the output speech data (response to a request); solve several tasks; are used for automatic information.

The structure of the intelligent dialog system. The architecture of the dialog system is presented as follows. The caller makes a speech, producing a noisy acoustic signal; the speech recognition engine converts it into a dictionary sequence. Automatic speech recognition is the process of converting a speech signal into a text stream. In a broad sense, the speech recognition involves the determination of its semantic content. The semantic decoder converts a dictionary sequence into an abstract representation of the client's speech. The program that controls the dialog ensures that the client's goal is fulfilled, saves a hypothetical speech act coming from the user, and keeps a relevant record of the user's actions. Depending on what stage the dialog process is at, the program produces a speech act that comes from the system. The speech act is converted into an output message by means of a speech stream generator, and finally into speech by means of speech synthesis.

Speech synthesis is understood as a sound representation of any information that is perceived by a person as speech. Technologies for continuous speech recognition and text-to-speech synthesis include a keyword search method. Speech analyzers find key words in the course of conversation, which are the connecting links for the flow of phonemes in speech. In conclusion, the user gives a response (reacts), submitting new data to the input, and the cycle of actions repeats again.

In conclusion, it is worth noting that in order to develop a suitable, efficient, easy to use spoken dialogue systems need to consider how technology transfer, recognition and synthesis of speech, correct understanding of the language, the dialog control and accounting of all components of information exchange between people that allows you to organize your computer to communicate with humans in natural language. Dialog systems will only be effective if they are familiar to the user, adapted to him. A carefully structured approach to the development of conversational dialog systems can lead to the emergence of new advanced technologies for a successful future person (for example, an automobile navigation system, a "smart" local cellular radio system, multimodal systems). The success of their implementation will depend directly on the level of quality that they can offer to users. 


\section{METHODS AND ANALYTICAL TOOLS IN THE ADVERTISING

\section{SECTION 2.}

\section{DATABASE MANAGEMENT SYSTEMS}

\subsection{Database models}

A database management system (or DBMS for short) is a software that is used to create and work with databases. The main function of the DBMS is data management (which can be both in external and in RAM). The DBMS necessarily supports database languages, and is also responsible for copying and restoring data after any failures.

As for the classification of databases, there are various options.

For example, you can divide databases by data model: hierarchical (have a tree-like structure), network (similar in structure to hierarchical), relational (used to manage relational databases), object-oriented (used for the object data model), and object-relational (a kind of merger of relational and object-oriented databases).

Or, if the division is based on where the DBMS is located, they can be divided into local - the entire DBMS is located on one computer, and distributed - parts of the database management system are located on several computers.

File-server, client-server, and embedded - these are the names of DBMS, if you divide them by the method of accessing databases. File-server DBMSs are already considered obsolete at the moment; basically, there is a use of client-server (DBMSs that are located on the server along with the database itself) and embedded (which do not require a separate installation) systems.

The information that is stored in databases is not limited to text or image files only - modern versions of the DBMS also support audio and video file formats.

DBMS use different data models. The oldest systems can be divided into hierarchical and network databases - these are pre-relational models.

The hierarchical model. In a hierarchical model, elements are organized into structures that are linked by hierarchical or tree-like relationships. A parent element can have multiple child elements. But a child element can only have one ancestor. IMB's Information Management System is an example of a hierarchical DBMS.

The hierarchical model organizes data in the form of a tree with a hierarchy of parent and child segments. This model implies the possibility of the existence of identical (mostly child) elements. The data here is stored in a series of records with value fields attached to them. The model gathers together all instances of a particular record as "record types" - they are equivalent to tables in the relational model, and 


\section{METHODS AND ANALYTICAL TOOLS IN THE ADVERTISING AND PUBLIC RELATIONS INDUSTRY}

individual records are equivalent to table columns. To create relationships between record types, the hierarchical model uses a parent-child relationship of the form 1: $\mathrm{N}$. This is achieved by using a tree structure - it is "borrowed" from mathematics, just like the set theory used in the relational model.

Hierarchical database systems. As an example of a hierarchical data model, consider an organization that stores information about its employee: name, employee number, department, and salary. The organization can also store information about its children, their names and dates of birth. The data about the employee and his children form a hierarchical structure, where the information about the employee is the parent element, and the information about the children is the child element. If an employee has three children, then three children will be associated with the parent element. In a hierarchical database, a parent-child relationship is a one - to-many relationship. That is, a child element cannot have more than one ancestor.

Hierarchical databases have been popular since the late 1960s, when IBM introduced its DBMS "Information Management System. The hierarchical schema consists of record types and parent-child types»:

A record is a set of field values.

Records of the same type are grouped into record types.

A parent-child relationship is a 1:N relationship between two record types.

A hierarchical database schema consists of several hierarchical schemas.

Network model. In a network data model, a parent element can have multiple descendants, and a child element can have multiple ancestors. Records in such a model are linked by lists with pointers. IDMS ("Integrated Data Management System») from Computer Associates international Inc. - an example of a network DBMS.

The hierarchical model structures the data in the form of a tree of records, where there is one parent element and several children. The network model allows you to have multiple ancestors and descendants that form a lattice structure.

The network model allows you to model the relationships between elements more naturally. Although this model was widely used in practice, it never became dominant for two main reasons. First, IBM decided not to abandon the hierarchical model in extensions for its products, such as IMS and DL / I. Secondly, after a while it was replaced by a relational model that offered a higher-level, declarative interface.

The popularity of the network model coincided with the popularity of the hierarchical model. Some data is much more natural to model with multiple ancestors for a single child. The network model allowed us to model many-to-many 
relationships. Its standards were formally defined in 1971 at the Conference on Data Processing Systems Languages (CODASYL).

The main element of the network data model is a set, which consists of a record-owner type, a set name, and a record-member type. A subordinate-level record ("member record") can perform its role in multiple sets. Accordingly, the concept of multiple parent elements is supported.

A senior-level record ("owner record") can also be a "member" or "owner" in other sets. The data model is a simple network, connections, and record intersection types (in IDMS, they are called junction records, i.e. "cross records"). As well as sets that can combine them. Thus, the complete network is represented by several paired sets.

In each of them, one record type is the "owner "(the" arrow "of the relationship departs from it), and one or more record types are" members "(the"arrow" points to them). Usually there is a 1:M ratio in the set, but the 1 ratio is also allowed:1. The CODASYL network data model is based on mathematical set theory.

Known network databases:

TurboIMAGE;

IDMS;

Built-in RDM;

Server-side RDM.

\subsection{Relational databases. Basic concepts}

In a relational model, unlike a hierarchical or network model, there are no physical relationships. All information is stored in the form of tables (relations) consisting of rows and columns. And the data in the two tables is linked by common columns, not by physical references or pointers. There are special operators for manipulating data series.

Unlike the other two types of DBMS, relational data models do not need to look at all the pointers, which makes it easier to perform queries for fetching information compared to network and hierarchical DBMSs. This is one of the main reasons why the relational model was more convenient. Common relational databases: Oracle, Sybase, DB2, Ingres, Informix, and MS-SQL Server. In the relational model, both objects and their relationships are represented only by tables, and nothing more.

RDBMS is a relational database management system based on the relational model of E.F. Codd. It allows you to define the structural aspects of data, relationship 
processing, and its integrity. In such a database, the information content and relationships within it are presented in the form of tables - sets of records with common fields.

Relational tables have the following properties:

All values are atomic.

Each row is unique.

The order of the columns is not important.

The order of the rows is not important.

Each column has its own unique name.

Some fields can be defined as key fields. This means that indexing will be used to speed up the search for specific values. When the fields of two different tables get data from the same set, you can use the JOIN statement to select the related records of the two tables by matching the values of the fields.

Often, the fields will have the same name in both tables. For example, the "Orders" table may contain pairs of "Customer ID" and "product code". And in the "Product" table, there can be pairs of "product code" and "price". Therefore, in order to calculate a receipt for a specific customer, you need to sum up the price of all the products purchased by them, using JOIN in the "product code" fields of these two tables. These actions can be extended to combine multiple fields in multiple tables.

Since the relationships here are determined only by the search time, relational databases are classified as dynamic systems.

\section{Comparison of three models.}

The first data model, hierarchical, has a tree structure ("parent-child"), and supports only one-to-one or one-to-many relationships. This model allows you to quickly get data, but is not flexible. Sometimes the role of an element (parent or child) is unclear and is not suitable for a hierarchical model.

The second, the network data model, has a more flexible structure than the hierarchical one and supports many - to-many relationships. But it quickly becomes too complex and inconvenient to manage.

The third model, relational, is more flexible than hierarchical and easier to manage than network - based. The relational model is most commonly used today.

An object in a relational model is defined as the position of information stored in a database. The object can be tangible or intangible. An example of a tangible object is an employee of an organization, and an example of an intangible entity is a customer account. Objects are defined by attributes - an information display of the 


\section{METHODS AND ANALYTICAL TOOLS IN THE ADVERTISING AND PUBLIC RELATIONS INDUSTRY}

object's properties. These attributes are also known as columns, and a group of columns is known as a row. A series can also be defined as an instance of an object.

\subsection{Database architecture. Functional architecture of automated data processing systems and dialog interaction with the user}

Database architecture - a set of structural components of the database, as well as tools that ensure their interaction with each other, as well as with the end user, system personnel. This definition reflects one of the most important functions of information storage-providing the ability to abstract database information. It forms the current approach to data architecture. This raises a new question: what is the purpose of data abstraction? Provided by the system, they (abstractions) will be the main means of supporting the independence of maintaining information stores (in other words, databases) by different groups of end users. In another way, this is called the independence of the system data.

The architecture of database management systems will vary depending on the variety of the latter. Today, there are two types of databases: centralized; distributed. We invite the reader to get acquainted with the features of each of the varieties below.

Centralized databases. The main difference between these databases is that they are stored in the memory of a single computing system. But if the database, in turn, is a component of computer networks, then distributed access to databases becomes possible. That is, the database will be open to users of electronic computers connected to this network. Such use is typical for local computer systems created on the basis of organizations and companies.

Distributed databases. What is important to know about distributed database architecture? Such databases consist of several parts stored in different computers of the same network. Perhaps the information here will be duplicated, intersect. What is convenient, the user of a distributed database does not need to know how the elements of the information storage are located in the nodes of such a network. Most often, he perceives this complex of information as a whole. How to work with such a database? Using a distributed database management system (RDBMS). Its system directory will describe the information contained in the data warehouse, the basics of its placement on the network. In turn, the directory itself can be decomposed, placed in various nodes of the common network. The components of a distributed database are placed on separate computers connected to it. They are controlled by their own (local) DBMS of electronic computing devices. It is important to note that such local 
information storage management systems do not necessarily have to be the same in different nodes of the shared network. However, combining these various local databases into a single system is a very difficult scientific and technical task. For its successful solution, a whole complex of experimental measures and theoretical developments was required.

Database types by the method of access to them. The database architecture will also differ in how the information stored in the storage is accessed: Access is local. Remote (network) access. The latter type of access involves dividing the architecture of such systems into two more variations: The "file server" type. Type "client-server". Again, we invite the reader to understand the presented varieties in more detail.

The file server database. Such an architecture of database complexes involves the allocation of one of the devices of the computer network as the central one. It will be considered a file server. A shared, centralized database is stored on the host machine. Other network devices act as workstations that support user access to the main database.

In the file server system, each user has the ability to run an application located on the host machine. Moreover, only a copy of this program will open on his device. According to user requests, the files of the central database (located on the server) are transferred to the computers-workstations. That's where the information is processed. Users who work with a shared database have a local copy of it on their computers. This copy is periodically updated as the main storage on the server is filled with fresh information. This architecture of database systems is most typical for networks to which a small number of users are connected. For its implementation, it is typical to use personal DBMS (for example, Paradox, dBase). The disadvantage of the architecture is the critically low performance of the system when multiple users simultaneously access the same data.

The "client-server" database. It also assumes that there is a machine in the network that will be the main one. However, the client-server database architecture has its own special feature. The main computer not only stores a centralized database, but also provides the bulk of the processing of the data required by the user. The technology divides the system into two parts: the server and the client. The latter will provide an interactive service, while the server one will provide information sharing, data management, security, and administration. What does the architecture of clientserver databases imply? The client application here forms and sends a request to a remote server computer, where the centralized information storage is located. It (the query) is compiled in a special SQL language-the standard for accessing the server 


\section{METHODS AND ANALYTICAL TOOLS IN THE ADVERTISING AND PUBLIC RELATIONS INDUSTRY}

when using relational databases. After receiving the request, the remote server redirects it to the SQL server. This is the name of the program responsible for managing the remote database. It ensures the execution of the request, provides the client with the required results for it. Thus, all request processing here will take place on a remote server. To implement such an architecture, you need to use multi-level DBMS. Their second name is industrial. Such DBMS are able to organize a largescale information system consisting of a large number of users.

Three levels of DB architecture. The database architecture is divided into three main levels - three degrees of description of the database elements: External. At this level, the information is perceived by users. Internal. At this level, information is perceived by operating systems, DBMS (database management systems). Conceptual. Here, the external level of the database system architecture is mapped to the internal level, ensuring their necessary independence from each other.

\subsection{Modern approaches to the collection, storage and use of information in the field of business}

Working with a Microsoft Access-level DBMS both at the beginner level and at the level of a qualified user is considered appropriate for relatively small amounts of processed information (up to $1 \mathrm{~GB}$ ). For more complex work options that do not require the analysis of significant amounts of information to develop the right solution, data warehouses are used.

A Data Warehouse is defined as a domain-specific, integrated, time-dependent data set designed to support decision-making by different user groups. The organization of the storage is aimed at the meaningful analysis of information, and not at the automation of business processes.

The object orientation property defines the architecture for building the storage and the design principles of the data model. Integration means that, for example, data about customers, departments, and products obtained from various sources is stored consistently and centrally.

The storage contains historical data, or a time-dependent dataset. In other words, if the most recent values are presented in the operational sources (for example, the current name of the client or its physical address), then the data warehouse will contain all their history, indicating the period when this or that data was up-to-date.

The data warehouse is characterized by a large volume and complex Data relationships. The data in the storage is not updated or changed, but only reloaded and read, which allows us to talk about their immutability and integrity. 


\section{METHODS AND ANALYTICAL TOOLS IN THE ADVERTISING AND PUBLIC RELATIONS INDUSTRY}

Along with the information that directly reflects the state of an object or system management Data Warehouse are stored and the metadata (data about data), reflecting:

- structure and content of the storage;

- relationships between data;

- correspondence between the source and output data;

- statistics on data loading and usage in the storage;

- information about archiving and encoding data, etc.

Data warehouses are most widely used in the banking sector, where their users are representatives of the bank's top and middle management, analysts, employees of financial analysis and marketing departments. Within the data warehouse, tasks such as customer base analysis, sales analysis and revenue analysis, as well as liability and asset management are performed.

There are several approaches to analyzing data in storage.

The main ones are considered to be:

- interactive data analysis [On-Line Analytical Processing, OLAP] - a computer application that supports multidimensional representation and visualization of data for the purpose of their analysis and preparation of reports. Currently, the software market offers a large number of OLAP systems, the developers of which are well-known companies, for example, IBM, Informix, Oracle, Microsoft, Sybase;

- periodically issued reports [Reporting] - reports in standard forms;

- Ad-Hoc Reporting-the ability to get quick access to a relational database for responding to queries generated by managers;

- Data mining - the process of analyzing large data sets, used to discover the relationships between their various elements and find hidden patterns.

Let's take a closer look at the Data Mining technology. This term is translated as "production" or "excavation" of the data. The activity of any modern enterprise is accompanied by the creation of a large array of unstructured and heterogeneous data (quantitative, qualitative, textual). The results of processing such data should be specific and clear, and the tools should be easy to use.

The modern Data Mining technology is based on the concept of templates that reflect fragments of multidimensional relationships in data. The patterns found should reflect previously unknown, non-trivial patterns in the data that make up the so-called hidden knowledge. 


\subsection{CRM-business model}

CRM (Customer Relationship Management). Despite the fact that the term itself appeared quite a long time ago (in the second half of the 1990s), many companies do not understand the true strategic nature of CRM. For example, some banks think that we are talking about direct mail, credit cards or a detailed database of customers, while others associate CRM with a support service or call center. Some consider CRM as a variant of a comprehensive front office aimed at developing sales channels in the online environment. A study by CRM-Forum revealed the following three factors that explain this lack of understanding of CRM:

- lack of a clear generally accepted definition of the role of CRM in the company;

- focus on information technology rather than the benefits it provides in building customer relationships;

- a wide range of tools and services often offered by IT vendors under the guise of CRM. Without going into a terminological discussion, here is the definition of CRM proposed by Adrian Payne, professor of service marketing and relationships at Cranfield University (UK): "CRM is a strategic business model aimed at creating and maintaining a suitable relationship between a company and its business partners." (Adrian Payne's "CRM Guide"). For a deeper understanding of the issue, we will try to determine the key meaning-forming principles of the CRM strategy.

Principle 1: personalization, or a segment of a single customer.

Today, the market is overflowing with depersonalized, and sometimes absurd, offers that cause a negative reaction of rejection. The reason for this situation is that traditional marketing treats customers as nothing less than an advertising audience. At the same time, banks often forget that a potential customer today can, without hesitation, go to your competitor with a single click on the Internet. The only thing that can attract the customer's attention is attention to the customer. Therefore, the more personalized banking services are, the more success can be expected.

Principle 2: The customer as a business asset.

Meeting the personalized expectations of each client is achieved only if the company treats its customers not as an impersonal advertising audience, but as business assets of the company. Such a position mobilizes all the internal resources of the company, stimulating not only the retention of profitable customers, but also the development of relationships with them.

Principle 3: Retain and develop profitable customers. 


\section{METHODS AND ANALYTICAL TOOLS IN THE ADVERTISING AND PUBLIC RELATIONS INDUSTRY}

We must admit that not all customers are equally profitable (remember the Pareto principle, which is that $20 \%$ of customers give $80 \%$ of all sales). For any bank, a profitable customer is a loyal and regular customer. Such a client not only generates income by constantly using your services, but also acts as a partner, attracting new customers and thereby reducing the cost of attracting them. At the same time, we should not forget that both the imbalance of attention towards attracting new customers and the obsessive desire to increase the loyalty of existing customers are equally dangerous for the company in the future. These two processes are strategically important, and both are equally important. A good motto here, perhaps, is the following: we attract new customers, we retain old ones - we are friends with everyone, but with everyone in different ways.

Principle 4: A cross-functional approach to marketing.

Within a function-oriented company, marketing planning is carried out by separate specialized departments, which, as a rule, do not take into account the consequences for the entire company as a whole. Moreover, their efforts are aimed at increasing sales and optimizing costs, rather than at personalizing banking products. To effectively implement a CRM strategy, it is necessary to make a transition from traditional departmental marketing to cross-functional marketing, which will allow all departments of the company to be involved in marketing processes, while defining the role of each business participant in customer service (both external and internal).

Principle 5: The business partner concept, or the six stakeholder markets model.

In the modern world, the market efficiency of a bank depends not only on properly built mutually beneficial relationships with its customers. Any bank today does not exist in a vacuum, but in a dynamic information environment with a huge level of competition, destroyed or rebuilt communication channels, ineffective traditional marketing methods, minimal barriers to entry into the business. Under the circumstances, it is impossible to ignore those areas of the market where the participants (stakeholders), not being your customers, directly or indirectly affect your success. And the main task here is to turn these partners into agents of the bank's business reputation. To optimize efforts aimed at building relationships with stakeholders, the so-called model of six stakeholder markets is proposed.

Principle 6: Proactive use of information to predict customer behavior.

It should be noted that the modern client is tempted by thousands of offers from all over the world. In such circumstances, it is at least unwise to hope that the client will inform you about their personal preferences: the client will not wait for your suggestions, he will simply go to a competitor who has managed to personalize 


\section{METHODS AND ANALYTICAL TOOLS IN THE ADVERTISING AND PUBLIC RELATIONS INDUSTRY}

their services to meet the needs of your client. The CRM strategy involves the proactive use of information that allows you to make such preventive offers to the client that would meet their requirements as much as possible. Moreover, the proactive use of information is the basis for the implementation of the "Zipper" technology proposed by IDS Scheer, which means that a bank employee should have a pre-prepared offer for any customer response, based, among other things, on the analysis of customer segments and predicted models of their situational behavior.

Principle 7: Using IT as a means of maximizing information.

Many banks associate CRM with the ordering of customer information, putting the functional requirements for the customer card at the forefront. However, for proactive personalization, thoughtful building of relationships with all stakeholders, maximum coordination and optimization of work processes, an appropriate IT infrastructure is required. We need an IT infrastructure that not only allows us to collect a complete set of information about customers and use it proactively, but also contributes to the construction of processes that connect the customer with the product in the process of sales and service.

Thus, in the context of the financial crisis, with ongoing and upcoming mergers and mergers, compliance with these principles is important not only for the implementation of the CRM strategy, but also for the survival of the combined banking structure as a whole. It should be noted that IT technologies do not play a leading role in CRM: they are an information environment, providing the company's employees with the necessary tools.

Of course, it is not easy to switch to a CRM strategy. Among the problems that arise during implementation, the following two most common and most important of them can be distinguished: first, as already noted, this is a lack of understanding of the principles of CRM; second, obstacles on the part of the company's employees.

As the practice of CRM implementation shows, in most cases, the obstacle to development is either a weak interest, or even rejection of CRM by the company's employees. In the top management environment, this factor is partly explained by the fact that CRM is perceived as a kind of enemy that can deprive the authorities and force them to delegate their own powers. In line management, CRM is regarded as an innovation that can radically transform the work model of the staff, changing the usual course of events while increasing labor costs.

This perception of CRM is psychological in nature and can be overcome only by means of explanatory work, the use of necessary motivational programs and open, tough support from the bank's shareholders. 
SECTION 3.

OFFICE APPLICATIONS

\subsection{Structure and purpose of the software}

A set of programs designed to solve problems on a PC is called software. The composition of the PC software is called the software configuration.

System software is a set of programs that provide effective management of computer system components, such as the processor, RAM, I / O devices, network equipment, acting as an "inter-layer interface", on one side of which is the hardware, and on the other - the user's applications. Unlike application software, system software does not solve specific application problems, but only provides the operation of other programs, manages the hardware resources of the computer system, etc.

These general-use programs are not related to a specific PC application and perform traditional functions: planning and managing tasks, managing I / O, etc. In other words, system programs perform various auxiliary functions, such as creating copies of used information, issuing reference information about the computer, checking the health of computer devices, etc.:

- operating systems (this program is loaded into RAM when the computer is turned on);

- shell programs (provide a more convenient and intuitive way to communicate with the computer than using the DOS command line, for example, Norton Commander);

- operating shells-interface systems that are used to create graphical interfaces, multi-programming, etc.

Drivers (programs designed to control the ports of peripheral devices, usually loaded into RAM when the computer starts) utilities (auxiliary or utility programs that provide the user with a number of additional services).

\section{Classification of software}

Traditionally, all software is divided into two classes:

1) System software (SPO);

2) application (user)software (PPO).

Let us single out another class (rather a group) of programs - special software for information and control systems. 


\section{METHODS AND ANALYTICAL TOOLS IN THE ADVERTISING AND PUBLIC RELATIONS INDUSTRY}

Application programs are designed to solve functional problems, they process information from various subject areas.

\section{This is the most numerous class of software products.}

Special software for information and control systems includes:

- database management programs (systems);

- programs for managing the language of the information systems interface;

- programs for collecting and pre-processing information (in information and measurement systems, for example, on-board systems).

Software of this class is often hidden as part of hardware drivers or is supplied as libraries of functional extensions of programming languages.

Therefore, such software is often referred to as system software.

We will consider this type of software as a separate class and will not consider it.

\section{Purpose of the system software}

The system software is designed for:

- creating an operating environment for the operation of other programs (in other words, for organizing the execution of programs);

- automation of the development (creation) of new programs;

- ensuring reliable and efficient operation of the computer itself and the computer network;

- diagnostics and prevention of computer equipment and computer networks;

- performing auxiliary technological processes (copying, archiving, restoring program files and databases, etc.).

This class of software products is closely related to the type of computer and is an integral part of it.

Software products of this class are mainly aimed at qualified users professionals in the computer field: system programmer, network administrator, application programmer, operator.

However, knowledge of the basic technology of working with this class of software products is also required for end users of a personal computer, who independently not only work with their programs, but also perform maintenance of the computer, programs and data.

Software products of this class have a general application, regardless of the specifics of the subject area.

System software products are subject to high requirements for reliability and adaptability of operation, convenience and efficiency of use. 


\section{Classification of system software}

The PDF traditionally includes:

- system control and

- system processing programs.

The control system programs organize the correct functioning of all the system devices.

The main system functions of control programs are:

- management of computing processes and computing complexes and

- work with the internal data of the OS.

As a rule, they are located in the main memory. These are the resident programs that make up the core of the OS. Control programs that are loaded into memory immediately before execution are called transitive.

Currently, system management programs are supplied by developers and distributors in the form of installation packages of operating systems and drivers of special devices.

Processing system programs are executed as special application tasks, or applications.

These programs are often delivered as distribution packages that include software. In addition to the basic programs that allow reconfiguration, the system software packages include special configuration programs called installation programs.

\subsection{Classification of software applications}

Software is understood as a set of software tools for creating and operating data processing systems using computer technology. Software also includes the entire field of software design and development.

It includes:

- software design technology;

- software testing methods;

- methods for proving the correctness of programs;

- analysis of the quality of the programs work;

- documentation of programs;

- development and use of software tools that facilitate the software design process, and much more.

The software life cycle is a period of time that begins from the moment of making a decision on the need to create a software product and ends at the moment of 


\section{METHODS AND ANALYTICAL TOOLS IN THE ADVERTISING AND PUBLIC RELATIONS INDUSTRY}

its complete decommissioning. This cycle is the process of building and developing software.

Classification of the software. Depending on the functions performed by the software, it can be classified into: system, application, and tool programming tools.

The system software is designed to control the operation of the computer. It is divided into basic, service and test.

Basic (general) software includes: operating systems(this program is loaded into RAM when the computer is turned on); shell programs (provide a more convenient and intuitive way to communicate with the computer than using the DOS command line, for example, Norton Commander); operating shells - interface systems that are used to create graphical interfaces, multi-programming.

The service software includes:

1. Drivers (programs that allow the operating system to access the hardware of a particular device. They are designed to control the ports of peripheral devices, usually loaded into RAM when the computer starts).

Here is a far from complete list of applications: connecting a mouse; keyboard; connecting plotters( plotters), scanners, printers, copiers (copiers), digitizers; connecting two computers via serial data ports; connecting modems for data transmission over telephone lines; connecting to a network of personal computers.

2. Utilities (auxiliary or utility programs that provide the user with a number of additional services).

The typical representatives of the utilities are:

- file managers or file managers;

- file, folder, and disk archivers;

- communication tools (communication programs) are designed to organize the exchange of information between computers;

- computer security tools (backup, antivirus programs);

- programs for dynamic disk compression. They allow you to increase the amount of information stored on disks by dynamically compressing it. These programs compress information when writing to disk, and restore it to its original form when reading.

- uninstallers of applications installed on the computer. They serve as a substitute for the standard Add dialog/Delete the Windows program. At the same time, they work approximately 5-10 times faster. There is a function to search for the application by keyword. 
Often utilities are combined into complexes, the most popular complexes are Norton Utilities, PC Tools Deluxe and Mace Utilities.

It should be noted that some of the utilities are part of the operating system, and the other part functions independently.

Test software is a diagnostic tool; a control tool that allows you to check the configuration of a computer and check the performance of computer devices, especially hard drives. The purpose of the tests is to detect errors in the operation of the computer or the computer system as a whole. Some programs perform various auxiliary functions: for example, issuing help information about the computer, checking the health of computer devices, cleaning the system registry, clearing the disk of temporary and unnecessary files, and editing the "Startup" folder, etc.

Programming tools are designed for creating programs. These include programming languages and systems that provide support for all stages of program creation: creating program source code in a programming language, compiling/interpreting, debugging, documenting, supporting, and maintaining software products.

Programming systems usually contain translators (compilers and interpreters); reference program libraries (functions, procedures), link editors, loaders, and debuggers.

The linking function consists of linking a program from many object modules. Since each of the object modules in the program was obtained as a result of a separate translation process that works only with one specific module, accesses to procedures and data located in other modules in the object modules do not contain actual addresses. The linking function is performed by a separate program called the link editor or linker. The link editor performs only the function of linking-assembling a program from many object modules and forming addresses in accesses to external points. The output of the link editor is a boot module.

To place the object program in RAM, free space in memory must be found and allocated. To perform this function, the loader program accesses the operating system, which executes its memory allocation request as part of the general memory management mechanism. Loader-a program that prepares an object program for execution and initiates its execution.

The debugger is a separate application designed to search for errors in the program. The debugger allows you to perform step-by-step tracing, track, set or change the values of variables during program execution, set and delete control points or stop conditions, etc. After all, in fact, what is the work of the debugger? To help 


\section{METHODS AND ANALYTICAL TOOLS IN THE ADVERTISING AND PUBLIC RELATIONS INDUSTRY}

the programmer localize the error to a specific function, a specific operation, a specific variable. The operating system can also help the debugger in this difficult task.

Application software combines a wide range of programs designed for various information systems. However, these programs cannot run without the operating system (OS) that creates the environment for them to run.

\subsection{Stages of database design in Microsoft Access. Types of inter-table relationships in Microsoft Access}

Microsoft Access is a DBMS designed for storing and searching information, presenting it in a convenient way, and automating frequently repeated operations. To implement a database in Access, you need to enter your own model through the design mode.

Creating a database consists of the following steps:

Defining the purpose of creating the data. At the first stage of database design, you need to define the purpose of creating a database, its main functions, and the information that it should contain. That is, you need to define the main topics of the database tables and the information that the table fields will contain.

The database must meet the requirements of those who will work directly with it. To do this, you need to define the topics that the database should cover, the reports that it should issue. Analyze the forms that are currently used for writing data, and compare the database that is being created with a well-designed, similar database.

Defines the number and structure of tables that the database should contain. One of the most difficult stages in the database design process is the development of tables, since the results that the database should produce (reports, output forms, etc.) do not always give a complete picture of the table structure.

When designing tables, you don't have to use Microsoft Access right away. First, it is better to develop the structure of the database on paper. When designing tables, it is recommended to follow the following basic principles:

1) The information in the table should not be duplicated.

2) There should be no repetitions between the tables.

3) Each table should contain information on only one topic.

When certain information is stored only in one table, then you will have to change it only in one place. This makes the work more efficient, and also eliminates the possibility of mismatch of information in different tables. For example, a single table should contain data about customers and their phones. 


\section{METHODS AND ANALYTICAL TOOLS IN THE ADVERTISING AND PUBLIC RELATIONS INDUSTRY}

Information on each topic is processed much easier if they are contained in independent tables. For example, addresses and customer orders are stored in different tables, so that when an order is deleted, the customer information remains in the database.

Defining the required fields in the table. Each table contains information on a separate topic, and each field in the table contains separate information on the topic of the table. For example, a table with data about teachers may contain fields with the name of the discipline, faculty, course, and group number. When designing the fields for each table, keep in mind:

- Each field must be associated with a table topic.

- It is not recommended to include data that is the result of an expression in the table.

- The table must contain all the necessary information.

- The information should be divided into the smallest logical units (for example, the fields "First Name" and "Last Name", and not the general field "First Name").

\section{Setting an individual value for each field.}

In order for Microsoft Access to link data from different tables, such as customer data and customer orders, each table must contain a field or set of fields that define the uniqueness of each record in the table. Such a field or set of fields is called a primary key.

Defining relationships between tables. After you distribute the data across the tables and define the key fields, you must select a schema to link the data in the different tables. To do this, you need to define the relationships between the tables.

It is advisable to study the relationships between tables in existing databases. To view the relationships in the database:

- open the file with the required database. (*. mdbx).

- select the "Data Schema" data command on the "Working with Databases" tab. A window will appear with the established links, but only if they have already been created and saved before.

There are four main types of information relationships between tables. A oneto-one relationship means that each value of attribute A corresponds to one and only one value of the associated attribute $\mathrm{B}$, and vice versa. For example, in the database of the personnel service of an enterprise, each value of the Staff Number attribute corresponds to a single value of the employee's full name attribute, and vice versa. The one-to-one relationship type binds the attributes Passport number and full name 
of the country's citizen. This type of relationship is usually used to separate tables that have a large number of fields, or to separate a part of the table that you want to restrict access to. In the graphic diagram of the domain model, this relationship is represented by single arrows and is denoted by $1: 1$.

A one-to-many relationship means that each value of attribute A corresponds to zero, one or more values of attribute B, and each value of attribute B corresponds to one and only one value of attribute A. For example, in the advertising agency database, a manager who oversees several advertising firms will be assigned a relationship of this type: one value of the manager's FULL name attribute corresponds to several values of the Advertiser's Name attribute. The designation of such a connection is $1: \mathrm{M}$, and is graphically represented by a single arrow on the one side and a double arrow on the many side.

A many-to-one relationship is the inverse of a one-to-many relationship. A many-to-many relationship means that each value of attribute A corresponds to several values of attribute $B$, and vice versa. For example, in the database of an advertising agency, the following relationship between the attributes describing this object is characteristic for an advertising company whose advertising can be placed in magazines, on radio and on television. One value of the Company Name attribute corresponds to several values of the Placement Name attribute, and each ad placement location can contain ads from several companies. The same type of connection connects the attributes of the Name of the advertising agency and the Company-advertiser, since the advertising agency works with several companies, and the advertiser can contact different agencies. Graphically, this type of M:M relationship is represented by double arrows. A many-to-many relationship between two tables in Microsoft Access is implemented by creating two one-to-many relationships using an intermediate table.

\subsection{Text editor, databases, spreadsheet, presentation and publication preparation tools}

1. Text editors are programs for creating and editing text documents (NotePad, WordPad).

Text editing is a set of operations for internal (semantic) and external (design) work on the text.

Text editors provide basic capabilities for preparing small and uncomplicated documents. They perform the following simple operations:

- enter alphanumeric information; 


\section{METHODS AND ANALYTICAL TOOLS IN THE ADVERTISING

- move through the typed text;

- insert or delete characters.

- select/delete/copy/move / paste a block;

Word processors are programs that provide a wider range of formatting options (fonts, tables, formulas) than editors.) and create documents containing different types of data (insert graphic, audio data).

At the level of a special PPO, programs that process texts are represented by specialized text editors and publishing systems.

Publishing systems are programs that automate the process of typesetting printed publications. Publishing systems are distinguished by advanced controls for the interaction of text with page parameters and graphic objects, but have weaker capabilities for automating text input and editing.

2. Spreadsheets are a software product designed for all kinds of computing tasks (Excel, Lotus).

The main purpose of spreadsheets is to process various types of data presented in tabular form, for example, planning and financial, accounting documents, small engineering calculations.

Spreadsheets perform the following functions:

- word processors for creating and formatting tables;

- mathematical processing of tabular data;

- visualization of results in the form of tables, charts, graphs.

The main advantage of spreadsheets, in comparison with word processors (where tables can also be maintained, small calculations and sorting can be performed), is that the content of some cells can change automatically in accordance with the change in the content of others.

Modern software products of this type have:

- calculation (computing) module, which is used to process data (text or numeric) in tables;

- a diagram module for creating presentation graphics, which allows you to create various types of diagrams based on numerical data obtained using the calculation module;

- a database module that implements access to external databases.

3. Database management systems (DBMS) are a set of software tools that provide the ability to create a database, access data, and manage a database (Access).

A database is a collection of interconnected data on machine media, organized in a certain way. 


\section{METHODS AND ANALYTICAL TOOLS IN THE ADVERTISING AND PUBLIC RELATIONS INDUSTRY}

4. Computer graphics systems are separate programs and hardware-software complexes that create and process various graphic images.

These include raster and vector graphics editors, and programs for processing three-dimensional graphics (ZD-editors).

In raster graphics, the image of a graphic object is described by the specific location and color of the points (pixels) attached to the grid (raster). When you edit bitmap graphics, the color of the pixels changes, not the shape of the lines.

In vector graphics, images are described using curved lines called vectors, as well as parameters describing their colors and location. When editing vector graphics elements, you can change the parameters of lines that describe the shape of graphic objects, you can transfer them, change their size, shape (this is done by mathematical transformations), and color, which will not affect the quality of their visual representation.

5. Integrated software-a software product that provides the operation of several heterogeneous systems with a single interface, as well as data exchange between systems and common standard parts (MSOffice, Works).

Individual programs, being a powerful tool for solving a range of applied tasks, cannot fully satisfy the user. For example, a sample of data provided by a DBMS can be conveniently processed using spreadsheets, and the results, designed in the form of visual tables, can be placed in a report, which is a text document that was compiled in a word processor. For the preparation of these documents and apply the integrated software.

Among the many integrated software packages, the most common is the Microsoft Office Office suite. It includes several applications that form a single environment for processing a wide variety of information that may occur in the office. It consists of:

- Word word processor;

- Excel spreadsheets;

- a package of preparation and demonstration of PowerPoint presentations;

- Outlook organizer and scheduler;

- Database management system (DBMS) Access and D. R.

6. Translators, games, entertainment. 


\subsection{Composite documents}

A composite (integrated) document is a document containing fragments of documents of different types. Fragments can be created in different Windows or MS Office applications and integrated (combined) in a single Word document.

It is performed by moving and copying objects from different applications to a Word editor document using the Mouse manipulator. For this method, a document (file)- source with object and document (file)- the receiver must be on the screen at the same time.

Moving an object is done as follows:

- select an object (by clicking the left mouse button);

- hold down the left mouse button on the object, move it from the source file to the desired location of the destination file, release the mouse.

Copying an object is performed in the same way as moving it, but with the Ctrl key pressed. In this

case, a "+"sign appears next to the object being copied. After the copy is finished, first release the mouse button, then the Ctrl key, otherwise the move operation will be performed, not the copy operation.

OLE (Object Linking and Embedding), literally translates as "object linking and embedding". This technology is developed by Microsoft for linking objects of various applications of the Windows operating system according to certain rules (protocol) of interaction. Some applications fully support the OLE technology, that is, they can be both sources and receivers of objects, for example, the WordPad and Word editors, while others-partially, for example, the Paint graphic editor can only be a source.

The links are automatically updated from the destination document with the Edit commandLinks, the Refresh key in the Links window. In this case, all adjustments automatically appear in the inserted linked object.

\subsection{Application Integration}

The usual history of the development of information systems in the company consists in the computerization of certain critical areas of the business on the principle of "extinguish where it burns". Since it is impossible to accurately calculate the impact of an automation project before it is implemented, and a simpler solution is cheaper, simple solutions are often preferred in the early stages of a company's development. The result is 2-3 programs that are neither technically nor organizationally related to each other. Up to a certain point in the development of the 
company and the business environment around it, this approach is justified and gives good results.

But with the growth of the business development company structure, increased competition in the market increases the value of completeness, efficiency and versatility of providing information about activities of the company. Data coming from separate systems is inconsistent or even unavailable at the right time. For example, if the warehouse and accounting system employees, without agreeing, entered different data about the same customer, then the task of collecting an elementary report on this customer from the warehouse and accounting data turns into a task that requires days, or even weeks of painstaking manual labor.

Different software solutions can also accumulate as a result of mergers, acquisitions and reorganizations of companies. Often such problems arise when forming holdings, which combine several companies with existing information systems.

The result of the "patchwork" information environment is low efficiency of its components, increased costs for support, operation and development, the inability to provide the required information, accounting and analytical support for business processes at the proper level and in time, respectively, losses in business efficiency.

With patchwork automation, it is almost impossible to see the real picture of the company's activities. Consequently, it is impossible to plan its activities and financial results in any reasonable way.

Here is a simple example: an enterprise engaged in transportation has two unrelated applications-order accounting, where all received orders for transportation and work on them are recorded (the Operational Department maintains them) and accounting, where all costs (both cash and non-cash) for the execution of orders for customers, as well as income from customers, are recorded. The different departments, for the "sameness" of inclusion of the names of customers no one was watching, accounting is not klassificeret work, which considers the costs and revenues, and in statistical classification works there, but the costs and revenues, they learn from the accounting Department.

In this case, the answer to questions such as " From what work performed for Customers, we received what income and what were the costs for them?» it can be obtained only by the huge efforts of employees of both departments within a few hours to several days (depending on the size of the company). They will need to generate reports that are available to their systems (Order Accounting - Customer Work, Accounting - Customers/Costs/Income), then-guess which client is called in 


\section{METHODS AND ANALYTICAL TOOLS IN THE ADVERTISING AND PUBLIC RELATIONS INDUSTRY}

which report (the names of clients in both programs may differ), then-raise documents on costs and income (invoices, receipts) in order to correlate costs and income from accounting with the completed work from the Order Accounting program.

As a result, routine issues of management accounting in the enterprise take up a lot of paid time of employees and do not give the management the information necessary to make decisions in situations that life puts before it. Despite the fact that the company has all the necessary information, it is often impossible or extremely difficult to get an answer to the required question. We can say that it is necessary to manage the enterprise in such a situation almost "blindly".

If these applications were integrated, this problem would not exist. The answer to such a question would take several minutes (that is, the time for generating the corresponding report).

That is why the management of companies is increasingly faced with the task of integrating existing enterprise "patchwork" software products into a single information space-the Corporate Information System (CIS).

A CIS is usually created for:

- implementation of the transition to a qualitatively new level of operational and strategic management decisions, due to the availability of complete and timely information about the activities of the enterprise;

- achieving transparency, maximum control and manageability of the company's activities for the owners and top managers of the enterprise;

- increase in the real income of the company as a result of restoring order in accounting operations and control over financial and material flows (for example, invoicing and control over accounts receivable);

- reduce the time between the work and the billing of customers, as well as control the timing of payment of these invoices;

- reduction of financial losses due to errors in the payment of invoices from contractors and suppliers, as well as due to the payment of fines and contractual sanctions due to the lack of control over the work of employees;

- the ability to conduct high-quality and detailed analytics, which allows you to determine the most profitable areas of business development.

At the same time, the approach to creating a CIS based on application integration allows you to:

- save previously made investments; 


\section{METHODS AND ANALYTICAL TOOLS IN THE ADVERTISING AND PUBLIC RELATIONS INDUSTRY}

- reduce the time and financial costs of maintaining and developing the company's information space;

- use the most effective systems of individual manufacturers to solve specific tasks;

- it is easy to expand and develop individual capabilities of existing information systems with the data already accumulated in them.

CIS gives you (at any time you need) an adequate picture of your business, and with the approach of integrating existing applications, you get it at the lowest cost.

Implementation options.

Integration of "everyone with everyone". This is the traditional approach to system integration, which consists in creating specialized data exchange interfaces for each pair of exchanging applications. This approach is good for a small number of applications. With a large number of them, it practically does not work. In addition, it does not allow you to build qualitatively new queries to the combined data, i.e. there is no qualitative gain from combining the data.

Integration at the user interface level. The approach is based on the fact that applications can use a friend in the same way that people use them, namely (using special tools) through the user interface (screen scraping). The most common variant is HTML-scraping, in which a special tool (for example, CrossWeave's Composite Application Platform) identifies the components of an HTML document resulting from a web application, and provides these components for reuse and integration.

This approach can be successfully used for relatively simple Web applications, but recently it has been increasingly replaced by Web services.

Integration at the data level. One of the most common approaches currently used is to create data warehouses (datawarehouses). It implies the support of data in special repositories, regardless of the business logic that generated them. Different applications can access the storage. In this approach, it is very important to have a well-documented (and rarely changing) data model.

It also has its drawbacks, which are primarily related to:

- increased requirements (and therefore the cost of the solution) for the hardware of the storage servers.

- the need to redo a significant (all work with the database) part of the applications (hence, an increase in cost and the possibility of making errors).

- the need for a single data schema for heterogeneous applications, which significantly limits the flexibility and development of systems. 
Integration at the enterprise application level. Application-level integration (EAI, Enterprise Application Integration) involves sharing executable code, rather than (unlike the previous approach) internal application data. Programs are divided into components that are integrated using standardized software interfaces and special middleware.

With this approach, these components create a universal software core that all applications use. For each application, only one interface is created to communicate with this core, which greatly facilitates the integration task. The resulting system is easier to maintain and expand. Reusing features within the existing environment can significantly reduce the time and cost of application development.

In addition, EAI integrates applications without making any modifications to them, which ensures that there are no errors in their operation.

The disadvantage of this approach is the complexity (not precisely estimated in advance) and, accordingly, the cost of work. 


\section{SECTION 4.}

\section{ANALYSIS OF ADVERTISING RESEARCH SOFTWARE FEATURES}

\subsection{Software for collecting advertising information}

One of the most popular methods of collecting primary marketing information is a survey, which is conducted through a personal dialogue with the respondent. In the field of advertising, the most common are telephone surveys, written questionnaires, personal interviews, and Internet surveys.

Computer technologies are used both in conducting surveys and at the stage of their design. An example of a survey design system is the Visual QSL package of Pulse Train Ltd., an interactive software package for creating surveys in the QSL language (Questionnaire Specification Language). In order to create questionnaires using Visual QSL, it is enough to be able to work in a Windows environment and know the possible types of questions. Questionnaires are created by filling out simple forms that are displayed on the screen after selecting the type of question. The form provides the user with the ability to enter all the necessary information on questions and answers, including any range of checks, text substitutions, etc. More complex commands are found in secondary menus and forms. This means that users with different levels of training can work in the system. The questionnaire is presented in the form of a tree, in which each question corresponds to an icon with the type and name. Questions can be copied, pasted, sorted, etc. The tree structure allows you to insert, delete, grow branches, add fragments from other questionnaires, etc.

The system can be used to automatically receive printed questionnaires. It allows you to select the language and appearance of the survey. This mode makes it possible to edit the questionnaire for those users who are more accustomed to working with its paper presentation.

When conducting telephone interviews, CAT/(Computer Assisted Telephone Interviewing) computer systems are used, which are a set of terminals (computer plus telephone) connected to a single network, the unity of which is supported by specialized software.

The selection of respondents for the telephone survey is carried out automatically, and the questionnaires are entered into the electronic database directly during the interview. 


\section{METHODS AND ANALYTICAL TOOLS IN THE ADVERTISING AND PUBLIC RELATIONS INDUSTRY}

CATI systems allow the supervisor to monitor the progress of the interview, monitor and correct the work of interviewers during data collection, which eliminates the possibility of data falsification and allows you to identify and correct the interviewer's mistakes in time.

The advantages of CATI computer systems (in comparison with the usual questionnaire survey) can also be attributed to the speed of obtaining results, the relatively low cost of the study.

One of the most well-known CATI systems is the Bellview CATI of Pulse Train Ltd. Among the users of Bellview CATI in Russia are such leading research companies as TNS/Gallup Media Russia, ROMIR, COMCON-2, Marketing Information Center (MIC), etc. For example, COMCON uses the CATI system to determine the media preferences of the radio audience, interviewing 1,000 people each week in Moscow. A questionnaire designed to determine which radio stations, when and to what extent respondents listen to, is programmed and entered into a central computer. From it, questions are issued to several terminals located in the same room. The interviewer operator dials a randomly generated phone number and conducts the interview by reading questions from the screen and entering the respondent's answers into the computer using the keyboard. In addition to the Bellview CATI system, the well-known telephone survey systems include the specialized NIPO CATI System software from Nipo.

TNS / Gallup Media has the most powerful telephone survey system in Russia, designed for 80 telephone lines.

When conducting an individual interview, computer systems CAP! (Computer Assisted Personal Interviewing) are used. The development of multimedia technologies has made it possible to use them both in conducting telephone surveys and in personal interviewing. In addition, there are systems specifically designed for handwriting computers (PEN-PC).

Currently, Internet surveys are becoming increasingly popular. The main advantage of Internet surveys is that they combine the best aspects of other methods of conducting surveys, namely: they allow you to quickly and inexpensively (as with a telephone survey) get information with a wide geographical reach of the audience (as with a written questionnaire). In addition, if necessary, you can establish feedback and contact the interviewers with the respondents on-line (as in a personal conversation). The Internet survey can be used for panel research. Using the browser, survey participants can access the website and fill out the questionnaire. Modern Internet survey systems include multimedia files and graphic images. 
To conduct interviews on the Internet and Intranet, you must have a browser program and special software.

However, it should be taken into account that in the framework of Internet research in Russia, not all layers of society are studied, but only some, limited in their economic and socio-demographic parameters. And in most cases, conducting Internet surveys is justified when studying narrow specific target audiences.

When conducting a survey, it is necessary to quickly process a large number of questionnaires, which is possible with the use of modern computer technologies. The main method of converting printed questionnaires into electronic form is scanning. Scanning is a technological process that creates a graphic image of a paper document. Form scanners are used to enter information from completed forms, questionnaires, questionnaires, and ballots. They are a kind of sheet scanners that allow you to scan a standard-sized sheet of paper in one operation. The next stage of processing is text recognition. The most well-known common programs that can recognize text printed in Russian are the domestic programs FineReader by Abbyy Software House and CuneiForm by CognitiveTechnologies (http://www.cuneiform.ru). A special feature of working with questionnaires is that you have to process a large number of documents of the same format, filled out by different people. To process the forms, a special application is included in the recognition programs. The created form template is superimposed on the scanned page. Data from the form fields filled in by the user can be recorded in a text file or entered in the database as records.

Abbyy SoftwareHouse has developed the ABB YY FormReader software product-a system for entering forms filled out by hand or on a printer, using ICR (Intelligent Character Recognition) technology. It can be used to recognize text typed on a typewriter or printer for 172 languages and written in block letters by hand - for 90 languages, as well as labels (items) and barcodes. In addition, the program allows you to perform automatic sorting of forms, export data entry results to TXT, DBF, Microsoft Excel, and database files, and save images as PDF files.

In addition to text recognition programs, there are special programs for processing the results of the survey. An example of such a program is the Bellview Scan system of Pulse Train Ltd., which allows different types of users to work: Administrator (Administrator), Editor (Editor) and Scanner (Scanner). It performs the entire form processing cycle: scanning, recognizing, editing, verifying, and exporting data. 


\subsection{Software for analyzing advertising information. Software for media research and media planning}

Software for analyzing advertising information. It is convenient to present the data obtained in the course of research in the form of a table. One of the most common software products used as a tool for analyzing advertising research is the Microsoft Excel spreadsheet processor. It provides not only input, storage and correction of large amounts of information, but also automatic recalculation of results when the source data changes, output of output documents on the display screen.

Software for media research includes systems for collecting and analyzing data about the TV and radio audience. An example of such a system is the Polar program.

To analyze the accumulated data on the behavior of the audience of TV viewers, the PaloMARS system can be used, which makes it possible to estimate the size of the audience of individual programs, blocks, ad outputs and time intervals in the broadcast grid.

Overview and features of computer graphics programs. One of the well-known programs for raster computer graphics is Corel Photo-Paint, which is used to work not only with printed, but also screen graphics.

The computer graphics program Micrografix Picture Publisher has very specific features. Among them are image collapsing, low-resolution "substitutes", contact sheets, and the function of creating thumbnail copies. Picture Publisher has a significant number of filters. The program has extensive capabilities for creating graphics for computer networks, including support for high-compression animation files.

Adobe InDesign. Its advantage is that it provides full integration with other Adobe design programs. InDesign allows you to make the layout and design of printed products easier than in other graphics programs.

Today, the vast majority of designers use the computer graphics program Adobe Photoshop. Today, there are many versions of this program that differ from each other in visual and technical capabilities. Photoshop CS5 has one of the richest sets of electronic tools. The Photoshop CS5 package is tightly integrated with Adobe InDesign. Today, Photoshop is a kind of standard raster graphics program.

Many computer users are familiar with the design programs that are part of the Microsoft Office suite and are well integrated with other office programs.

With the MS Publisher desktop publishing system, a computer user can quickly learn how to create layouts for ads, business cards, newsletters, brochures, and Web pages, even if they have never done graphic design before. 


\section{METHODS AND ANALYTICAL TOOLS IN THE ADVERTISING AND PUBLIC RELATIONS INDUSTRY}

In the luggage of computer users, you can find a number of interesting programs that are designed to create and dynamically display electronic slide movies. One of them-PowerPoint, which is part of Microsoft Office, provides powerful tools for developing slide movies, several electronic "masters", presentation templates of various types with a ready-made structure, design and content.

The MS Excel computer program belongs to the class of table processors and can be used to build business graphics objects based on digital data compiled in a spreadsheet.

One of the well-known vector graphics programs is Adobe Illustrator. A great convenience for designers who are already familiar with other Adobe graphics packages is that the Illustrator interface strongly resembles Photoshop. The program has the ability to work with both vector and raster graphics, importing files of various formats. For Web page creators, the standard Adobe Illustrator package includes a set of colors for the Internet.

Today, many designers use one of the most powerful graphics programs, Corel DRAW. Vector-oriented editor. It provides users with tools for solving a wide variety of tasks-from text processing and illustrations to creating multi-page publications and computer animation. A well-developed interface, high-quality images, and extensive color separation capabilities allow you to use Corel DRAW in various areas of graphic design, publishing, and advertising.

In Web design, specialized programs designed to work with three-dimensional graphics are becoming increasingly common. One of the most powerful 3D graphics packages is 3D Studio MAX. The program provides the user with a full range of possibilities for creating three-dimensional scenes and computer animated videos, etc. This package allows you to use other programs at different stages of creating threedimensional graphics - Corel DRAW, Photo-Paint, etc.

Computer-aided design (CAD) systems are widely used in industrial product design and architectural design. One of the most common computer CAD programs is the AutoCAD program, designed for professional use. AutoCAD is a high-level program that implements a wide range of functions that are necessary for a designer or design artist. 


\subsection{Application of the SPSS statistical Analysis package in Advertising Research}

To work with the statistical computer program SPSS, you first need to have the results of the survey (completed questionnaires). For the selected individual questions, or for all questions of the questionnaire, it is necessary to identify statistically significant patterns; determine the statistical distribution of the answer options; evaluate the proximity to the normal distribution law. The SPSS program allows you to print the necessary tables, build graphs, charts and / or histograms.

After studying the data obtained and making final conclusions, it is necessary to form a final report with a detailed analysis of the results of the marketing research. 


\section{SECTION 5.}

\section{EVALUATING THE EFFECTIVENESS OF ADVERTISING IN MAILING LISTS AND TELECONFERENCES}

\subsection{Banner-the main advertising medium. The effectiveness of the banner. Payment forms for banner ads}

As a rule, a banner is a rectangular graphic image, although there are banners of a different shape. Usually, the banner is placed on the page of the site-advertising platform or in a letter that is sent by e-mail. A hyperlink from it leads to the advertiser's website. The advantages include:

Large audience coverage. The higher the site traffic, the more likely it is that the banner will attract more users. But this will only work if the advertiser correctly selects the site theme and the place to place the banner on the page.

Positive impact on brand awareness. Display ads are no longer attracted by text, but by a bright, flashy image. Therefore, the image placed on the banner will unconsciously remain in the user's memory, which will increase brand awareness.

Focus on the target audience. To attract only those users who are interested in the promotional offer can be used to target graphical ads in settings of contextual advertising Yandex and Google. This allows you to set the necessary settings based on the portrait of a potential buyer, which will bring only high-quality traffic to the site.

Instant performance. Banner ads can lead users in the first hours after launch. The result depends only on the correct design, placement and configuration of the ad.

Easy operation. You can make changes and monitor statistics at any time online.

Banners, as a marketing tool, can be called multitasking. Therefore, by including them in the arsenal of an advertising campaign, several goals are achieved at once. In total, there are 5 tasks that banner ads can handle:

- attracting attention;

- create a pleasant experience;

- ability to arouse interest;

- encourage users to click through to an external site;

- directing the user to perform a certain action (buy a product, sign up for a seminar, etc.). 


\section{METHODS AND ANALYTICAL TOOLS IN THE ADVERTISING AND PUBLIC RELATIONS INDUSTRY}

Banner exchange is relevant if the advertiser is the owner of a full-fledged high-quality website. The essence of this tool is that two or more site owners place banners on their sites by mutual agreement. To simplify the procedure, entire banner exchange networks are created, which allow you to quickly reach users interested in cooperation.

The standard functions of banner exchange networks include:

Accumulation of the number of impressions. When a banner of a third-party company participating in the banner exchange program is published on the site, a special counter of the system records the exact number of impressions that it will remain due.

Sales of impressions. If you accumulate enough impressions, you can use them to publish your own ads and sell them. However, not all networks provide this opportunity, since this way the site owners deprive the administrators of banner exchange networks of their main earnings.

Control over statistics. Statistics allow you to monitor the effectiveness of participation in the program.

When choosing a banner exchange network, you need to pay attention to its orientation. There are both universal and thematic services. To attract the target audience, it is better to choose highly specialized networks. In addition, it will save the owners of solid companies that value their reputation from the appearance of incorrect advertising on their site.

Depending on the technology used, banners can be divided into two main groups: traditional and rich-media.

Traditional banners. Banners of this type are graphic images in GIF or JPG format. The banner can be static (contain a simple image) or animated (contain moving elements).

The movement effect is achieved by quickly changing several images on the banner in succession. The use of animation allows you to draw the user's attention to the banner, which increases its effectiveness as an advertising medium.

Rich-media banners. This is a new generation of banners. When creating them, the emphasis is on Flash, Java, and other technologies. Unlike traditional banners based on bitmap (dot) graphics, Flash banners use vector graphics (areas of different colors and the dynamics of their changes are set mathematically). This allows you to create high-quality animation effects while keeping the file size relatively small, which is very important for a banner. 
Another significant step forward compared to traditional banners is the ability of the user to work with rich-media as with a mini-site. Traditional banners may contain images of controls (buttons, links, drop-down lists, etc.), but this is nothing more than a deception of the user. All these elements do not work, and when you try to click on any of them, the user simply gets to the advertiser's site. The technologies used in rich-media banners allow you to make these elements work. The user can directly select the section of the advertiser's website that they want to visit, view the list of products and services offered, and even play an online game.

Rich-media banners allow you to include sound effects as well. The sound can be played continuously at the same time as the banner is displayed, or only during certain user actions (button clicks, etc.).

Rich-media banners can be effectively used to work with the audience already on the side of the advertising platform. In such a banner, a calculator can be built in to calculate the cost of a car or an insurance policy. Without leaving the page of the advertising platform, the user can subscribe to the newsletter, fill out a questionnaire or participate in the lottery directly on the banner.

Thus, comparing traditional and rich-media banners, we can conclude that richmedia banners are more effective. Practice shows that this is true. However, traditional banners do not lose their meaning. There are several reasons for this:

- traditional banners are easy to make and can often be prepared in-house by the staff of even a very small Internet project;

- if a company orders the production of a banner, a traditional banner will cost it much cheaper than rich-media;

- traditional banners do not require any additional software from the user for their reproduction, while some rich-media banners can be played in the user's browser only if they have the appropriate programs installed. However, this restriction is becoming less and less significant, since in the latest versions of all the leading browsers, these programs are already built-in;

- the advertising platform is not always ready to accept the placement of a richmedia banner. If the entire site of the advertising platform is made using traditional technologies, then the rich-media banner may stand out too much against the background of the site content and distract or even annoy users.

The most common criterion for the effectiveness of a banner is its CTR (Click Through Ratio). This is the ratio of the number of clicks on the banner to the number of its impressions to users, expressed as a percentage. For example, if the CTR is $0.3 \%$, then for every thousand impressions of the banner, three clicks are made on it 
to the advertiser's site. It should be noted that for all the clarity and simplicity of measurement, CTR can not be considered as an absolutely adequate measure of the effectiveness of the banner. More information about this is described below.

The quantitative value of the CTR depends on the following factors:

- the content of the banner;

- the technology used in the production of the banner;

- the quality of the advertising platform;

- display focus settings;

- placement of the banner on the page;

- the number of impressions per unique user;

- banner format;

- the size of the banner (in bytes).

Floating banners. For the first time in the Russian Internet, floating banners were used by the RLE banner network (www.rle.ru). The network offered its participants an exchange of banner impressions, which, unlike regular banners, does not occupy a fixed place on the page, but is always located in the upper right corner of the screen, obscuring part of the site's content (the stroll banner).

If the user moves through the page by scrolling, the banner retains its position in the upper-right corner, moving synchronously with the scrolling. If the banner interferes with the user, he has the option to close it at any time. If the user does not respond to the banner for some time, it quietly disappears.

The cost of a banner does not have clear boundaries, because it is influenced by many factors. But to roughly plan the budget, you should consider:

The placement method. With a personal agreement, you can order a banner at a lower cost than the exchange can offer. Also, do not exclude the possibility of free placement of the banner on the network.

Territorial targeting. Impressions for residents of the capital will cost the advertiser more than for residents of sparsely populated regions of the country. This is due to the fact that residents of Moscow and the region are recognized as the most solvent buyers.

Subject matter. Niches where there is a high level of competition are more expensive to promote.

For banners to be more effective, the placement must be long-term. A shortterm ad campaign can only generate a small amount of traffic, since the conversion rates of banner ads range from 2-30\%. For this type of advertising, regular 
impressions are an inexpensive treat. The average budget for one banner is about 3000 rubles per month.

\subsection{Advertising in text blocks}

This is the very first form of advertising information distribution. It is a text accompanied by a link to the advertiser's page. This form is the simplest, but it has many limitations. Its use is currently limited only to those cases where the use of graphic advertising is impossible or undesirable. However, there are cases when this form is the most effective. In particular, this is contextual advertising on search engines. In this case, text advertising is not perceived by the consumer as advertising. This is due to the fact that when advertising on search engines, when the price is equal, text advertising is more effective than graphic advertising in terms of the number of responses.

The most obvious disadvantages of this form of advertising include the almost complete absence of an image component.

Among the advantages of text advertising is the ease of production, it loads faster, and it is seen by users with graphics disabled in browsers. But, most importantly, the text block is often associated with visitors not with advertising, but with the recommendations of the leading servers, which creates a greater credit of trust for it.

Text blocks are now used not only for advertising in mailings, where they are prevalent, but also directly on websites. In Runet, there is even a network for the exchange of text blocks-TX3 (www.tx3.design.ru).

Due to the specifics of text blocks, there are no special standards for them. There are only restrictions on the size of the text (sometimes the percentage of clickable text is also separately limited). For example, a text block - 5 lines of 72 characters. 5\% of the WEBRAITING catalog sites support this format. The format is mainly used in mailing lists. Or a text block - up to 50 characters. $19.1 \%$ of the catalog sites support this format. The format is mainly used on websites.

\subsection{Targeting ads on the internet}

The word targeting comes from the English "target", which means "target, targeting" in Russian. Targeted advertising - advertising aimed at a specific audience (target consumer). Targeted advertising allows you to target specific groups of consumers. 
Goals and objectives of targeted advertising.

The goals of targeted advertising are no different from the goals of any other communication channel:

Informing consumers about the company, product and its characteristics;

Sale of goods;

Entertainment of consumers, attracting attention;

Consumer education.

As for the tasks that targeted advertising performs, we have identified the following features:

Attracting the attention of narrow groups of consumers aimed at making a purchase;

Express information about the product (the consumer will receive the rest of the information, if desired, by clicking on the link);

Instant purchase or other targeted action (registration, call, bookmarking).

Types of targeting.

The main types of targeting for Odnoklassniki and Mail projects.Ru, VKontakte, Facebook, MoiMir:

geography;

demographics;

age;

Birthday;

marital status;

interests;

In contextual search ads that are displayed in response to a user's query, the main type of targeting is keyword targeting. At the moment, this advertising is considered the most effective in terms of attracting users who are ready to buy:

In Yandex and Google, you can display banners, text ads, and video ads using the following types of targeting:

- by keywords ("fashion design what", " interior design examples»);

- by gender and age (women 27-45 years old);

- by geography (city, region, country, world);

- by time of day (in staggered order, for example);

- by sites (youtube.com, avito.ru and so on);

- by interests (designers, builders, etc., only Google AdWords);

- by subject (real estate, finance, medicine, etc.);

- by mobile devices and apps (Google AdWords only); 
- by the frequency of ad impressions to a single user, and so on. The mechanism of targeting ads.

The most important thing in the work of targeted advertising is to get the most complete information about each user. Based on this information, the system will make a decision about the display of your ad. That is why the most common channel for targeting has become social networks, in which users voluntarily provide their personal data when registering.

Remember, the Vkontakte registration form contains fields such as gender, age, city, marital status, favorite movies, books, interests, and much more. Based on this data, the system allows you to configure all these parameters when selecting the target audience for displaying your ad.

After you have configured all the parameters, written the ad text and uploaded the image, your ad will be sent for moderation. As a rule, moderation takes no more than a day. It is important to note that the most important thing is not the launch of advertising, but the proper configuration of the parameters and characteristics of targeted advertising. Otherwise, spending the budget on advertising will be ineffective. 


\section{SECTION 6.}

\section{ANALYSIS OF THE EFFECTIVENESS \\ OF ONLINE ADVERTISING}

\subsection{Levels of evaluation of the effectiveness of Online advertising}

In recent years, the active development of the Internet has stimulated the spread of online advertising. Increasingly, the Internet is used simultaneously with television - both users and advertisers. The spread of the Internet does not replace other media, especially TV, but rather complements them. The Internet is becoming recognized as an important tool for influencing customers and preparing them for purchases. For example, a FEVAD-Mediametrie barometer study conducted in 2010 found that $78 \%$ of Internet users study product information on websites before making a purchase. The Internet also contributes to the emergence of new advertising platforms, such as social networks, whose influence and role in modern society is already difficult to underestimate, and the presence of companies in social media is becoming an integral part of their marketing strategy. The expansion of advertising opportunities thanks to the Internet leads to the emergence of new formats and methods of advertising aimed at the target audience. At the same time, the growing number of advertising formats and areas requires new methods for assessing the real visibility and effectiveness of advertising. New methods of targeted advertising based on behavioral stereotypes are emerging, which increases the effectiveness of advertising campaigns, and multimedia and video advertising open up opportunities for new consumer relationships with the brand, including in social media.

For effective monitoring of online advertising, special evaluation tools are needed.

1. Defining the goals of the online communication strategy. To be effective, the Internet must be included in the overall marketing strategy. There are many indicators that allow for a more specific and often more rapid assessment of online advertising. However, a wide range of indicators does not always provide a proper assessment of the effectiveness of a marketing strategy. Some advertisers face the risk of" information obesity" (infobesity). For advertisers, it is more important to bring together and compare data on various media (Internet, TV, radio, press, etc.), and not just evaluate the data using a wide range of indicators. Most advertisers 
emphasize the need for integrated evaluation and monitoring systems, especially in the following three areas:

Understanding ad reach and repeatability.

Analysis of the impact of advertising campaigns on the brand.

Assessment of the impact on sales.

More sophisticated advertisers develop strategies that cover all types of media. Thus, the strategy of working on the Internet should not be considered in isolation, but in terms of its contribution to the achievement of overall marketing and commercial goals.

Given that the goals may be different, it is necessary to identify and implement indicators that correspond to these goals. First of all, this is a list of various goals that can be set for an advertising campaign on the Internet.

Branding: The purpose of branding campaigns is to strengthen various components of the brand, such as awareness, image, or customer intent. These campaigns are usually part of a broader media strategy, and most often their cumulative effect is evaluated together with other media.

The work to increase customer loyalty is also carried out within the framework of branding and is aimed at expanding the experience of the consumer's relationship with the brand online, but with the specific goal of interacting directly with the Internet user.

The growth of offline sales (traditional types of sales) continues to be the ultimate goal of the brand promotion campaign, with the exception of image advertising. Achieving this goal may be more important for specific campaigns, which means that the assessment can be carried out with greater accuracy.

Online sales growth: These campaigns are primarily aimed at increasing sales on the brand's website or in partner networks. Such campaigns can also simultaneously pursue the goals of achieving the effectiveness of advertising and branding.

Determining the range of potential consumers is based on a result-oriented method, but does not pursue the goal of increasing online purchases. The goal is to study the range of people who use interactive Internet resources, such as games and questionnaires, for classification purposes.

Increasing the reach and repeatability of messages: as Internet penetration increases, it quickly becomes a media outlet that allows you to increase the impact of an advertising message. One of the tasks of Internet campaigns may be to expand the scope of the message and ensure repeatability in other media. 


\section{METHODS AND ANALYTICAL TOOLS IN THE ADVERTISING AND PUBLIC RELATIONS INDUSTRY}

Reducing the cost of attracting customers can be another goal of online campaigns. For result-oriented advertisers, it is the main one.

Different indicators can be used to achieve each of the above goals. The following is a basic, but by no means exhaustive list that provides an idea of the evaluation tools available to advertisers. In many cases, the same indicator can be used to assess the achievement of different goals.

2. Evaluating the contribution of the Internet to the achievement of branding goals. In addition to the CTR, several studies have evaluated the impact that the Internet has on brand awareness, memorability, and image. Although advertisers still tend to use television to build and increase brand awareness, many studies show the potential impact of the Internet on various components of a brand.

3. Impact on brand awareness. To determine the impact of advertising on brand awareness, Nielsen analyzed the impact of several campaigns shown on television and then on the Internet.2 It was found that in some sectors, such as the automotive and beverage industries, the Internet provided brand memorability twice as well as television. Such high Internet performance can be explained, in particular, by the number of advertising inserts.

4. Improving the brand image. Several studies have also identified the positive impact of the Internet on brand image. For example, an analysis of the McDonalds display advertising campaign in 2009 shows that an online advertising campaign increased brand identification by $10 \%$. Similarly, a campaign conducted by L'Oreal resulted in a $9 \%$ increase in brand identification.

Positive impact on the customer's intention. In a study of graphic advertising campaigns conducted by four advertisers from various industries, Mediametrie NetRatings found that the purchasing intentions of Internet users who viewed these advertising campaigns increased by $11 \%$.

Evaluating the impact of advertising campaigns. Conducting post-tests is still a reference method for evaluating the impact of advertising campaigns on the brand. Realizing this, advertisers are increasingly conducting special analysis on the Internet. Using metrics other than the CTR can help determine the impact of online advertising on branding.

\subsection{Managing interaction with internet users}

The nature of the user's interaction with the environment. The Internet user, as an object that is affected by advertising, is significantly different from the TV viewer or reader of newspapers and magazines. When a person who is tired after a working 
day is relaxed watching TV, you can hardly count on his attention. With this mode of interaction with the environment, it may take a few seconds before a person notices that instead of the movie he was watching, they started showing a commercial.

When a person reads a magazine or newspaper, his attention is more focused than when watching TV shows. Even if we are not talking about careful reading, but only about viewing the pages of the magazine, to quickly view the headlines of articles, a large degree of attention is required. When reading or viewing a magazine, the initiative to receive information clearly belongs to the reader, whereas the viewer is usually passive.

An even greater degree of involvement in the process is observed when a person views web pages. Most likely, he is not lying on the couch, but sitting on a chair or in an armchair. Before him is a computer-a device designed by engineers for work, and not by high-class designers for a comfortable holiday. Unlike the TV viewer, the web surfer looks carefully at the screen, and not somewhere nearby. Most likely, he is looking for something on the Internet. At least, all researchers agree that the main occupation of Internet users is the search for the necessary information. The degree of involvement in the process is maximum.

The user, whose entire attention is focused on the events unfolding on the screen, is an excellent object for online advertising. Unfortunately, this is not the case. As we said, this person is most likely looking for something. And if at the moment the user is interested in TVs and routers, all his energy is spent on the fact that from the abundant flow of information to select a small part of the one that he really needs. In such circumstances, he is unlikely to pay attention to advertising, say, operating systems, although it is quite possible that tomorrow he will be interested in this. But that's tomorrow, and today he needs routers and nothing else.

So the user at least some of the time distracted from his search, he / she is advertising must be very expressive; appearance of advertising needs to completely change the course of the thoughts, just to make him forget about what he's looking for, and click the banner.

In addition to the nature of the user's interaction with the environment, it is absolutely necessary to keep in mind that the effectiveness of network advertising can be affected by such a prosaic thing as network bandwidth. This is a reality conditioned by the principles of the Internet. And it's one thing for a person to wait a minute or even more for the information they know they need to load. He knows what his time is being spent for. It is quite another matter when a minute is spent on loading an advertising banner. And if you consider that when loading pages, 
advertising banners are usually pumped first, it turns out that a person simply has to wait patiently for the banner to be forwarded, and only then will the information he needs begin to arrive. It is unlikely that such delays work for the image of the company that placed the banner. And even more so, the person will not click on the banner, the long loading of which prevented him from working.

The design of the page where the banner is placed. The effectiveness of the banner is also affected by the design of the page on which it is placed: the graphic design of the page; the way information is organized on it.

Consider a simple example-searching for information on the Internet using the AltaVista search engine. When AltaVista displays a list of relevant links, the actual links appear on the screen first, and then the ad banner located at the top of the page is placed. As soon as the first links appear on the screen, we can go down and view the links without waiting for the banner to appear. AltaVista developers have taken into account the possibility of such a course of events, and the banner is duplicated at the bottom of the page. However, what prevents us from using one of the links in the middle part of the page? Click on this link and leave the search engine without seeing either the upper banner or the lower one. The example is more than typical. On other sites, you may encounter similar situations where the placement of the banner is organized in such a way that the user may well complete their task without seeing the banner.

In addition to such organizational issues, the graphic design of the page on which the banner is placed is also important. This is natural, since the ability of a banner to attract the attention of users cannot but depend on the environment in which it is located.

Thus, the effectiveness of an advertising banner depends on a lot of different parameters, including the number of banner impressions to the same user, the speed of changing images in animated banners, and much more.

\subsection{Price schemes of advertising placement}

At the moment, there is a whole set of pricing models for placing advertising media on the corresponding advertising platforms on the Internet. Due to the fact that IR has both similarities and differences in comparison with offline advertising, some of the models are unique and have no analogues in traditional advertising channels, and some are widely used outside the Network.

Fixed fee (Flat Fee). One of the most popular price models of advertising placement: fixed placement of ads for a given period of time. In this case, a fee is 
charged for the time of placing ads in a certain section of the site. Many sites place an advertiser's banner on one or more of their pages, charging a fixed fee per month, day, or any other specified period of time. The cost depends on the page traffic, the subject of the server, the location of the ad on the page.

By its type, this price model is similar to the placement of billboard advertising on the streets of the city, where the payment is also based on the time-for a week, a month, etc.

CPM (Cost per thousand). Cost per thousand ad impressions (in this case, the letter $\mathrm{M}$ in the model name means Millennium, that is, a thousand). This model is the most common price model in the Network. The calculation is based on the number of impressions counted by the program. When applied to banner ads, it is considered that the display was carried out if the user's browser loaded the banner (but the user may not see it). This situation is likely if the banner is loaded in an area of the page that does not fit on the screen, and the user, for example, goes to a link to another page, without bothering to fully study this one. In addition, it happens that the banner is very heavy (it weighs a lot in terms of the amount of information) and the user simply does not wait for it to load. The opposite situation is also possible, when the user saw the banner more times than the system showed (the browser can place the banner in the cache (the area of physical memory on the user's hard drive where images and other elements of the pages that the user views most often or at all are stored). Putting the drawing in the cache speeds up its subsequent loading, because it is taken not from the Internet, but from the local space) after its first download and show it again on another page without contacting the server). This model is also used for mailing lists.

CPM is often used to calculate the cost of advertising on television and radio. In Runet, servers that sell banner impressions have CPM ranging from $\$ 1$ to $\$ 50$.

All subsequent price models are unique and have no analogues in traditional advertising. They are based on data on the user's interaction with advertising, the website, and other mechanisms, including systems for placing requests and orders.

CPC (cost per click). Cost per thousand clicks. A pricing model (in which the advertiser pays directly for "clicks" on their ads) that applies to any type of advertising media. In Runet, servers that sell clicks usually have a CPC of \$200-300 per thousand clicks. CPC should not be confused with cost per user (CPV). The number of clicks can be greater than the number of visitors attracted by these clicks, and losses can be up to $50 \%$ or more. Clicks are counted on the publisher's side (site), and visitors are counted on the advertiser's side. 
CPV (cost per visitor). Cost per thousand users. This pricing model is similar to CPC, but it is more difficult to calculate (accounting can only be conducted directly on the advertiser's side) and therefore has become less widespread.

CPA (cost per action). A pricing model in which the advertiser pays the publisher who placed the ad for the specific actions of the attracted visitors. For example, the calculation can be made for the number of completed questionnaires, subscriptions to certain services, filling out applications, etc. This pricing principle, along with the CPA, is most often used in affiliate programs.

CPS (cost per sale). A pricing model in which the advertiser makes a calculation with the publisher who placed the ad, based on sales to attracted visitors. The principle is similar to CPA and is also used primarily in affiliate programs. The difference is that not only the purchase is recorded, but also the purchase amount itself. Accordingly, the payment is not a fixed price of the action, but a percentage of sales. So, an online store Ozon.ru -pays from 3 to $10 \%$, Amazon.com -from 5 to $15 \%$ of the sales amount for the buyers attracted by the web publisher.

Comparing the above price models, we can draw the following conclusions. From the point of view of the publisher, the first model is the most" safe", the last one is the least. This is due to the fact that in the first case (Flat Fee), he is guaranteed to receive a certain time agreed amount, in the second case, CPM-it depends on the attendance of your site that may unexpectedly fall in the third (CPC) - also depends on the performance of ads and nature of the proposed services in the last (CPS) from all the above factors and the level of implementation in the online shop of the advertiser, the competitiveness of the prices in the store, and many other factors, not directly related to the owner of the advertising platform. But this does not mean that the first model is the most preferred for the publisher. It all depends on the relative proportion of prices for each of the models and the type of product advertised. The advertiser is in a similar situation, but for him, from the point of view of "security", the price models need to be placed in the opposite order.

In theory, the models are quite clear and understandable, but in practice the situation is somewhat different.

It is quite common practice when a company pays, in whole or in part, to a partner (representative office, dealer, distributor) the costs of advertising its products. Payment is made on the basis of the submitted report on the conducted advertising campaign. The report may include, for example, the following item: "Placing an advertising banner on the site www.somewhere.ru". At the same time, in fact, the options for placing a banner can be very different: at the top or bottom of the page, on 
the side, it can be a dynamic or static banner. Depending on the location, the price varies greatly. According to the report, the company pays the partner to place the banner at the maximum cost.

As a rule, all sites give a certain discount for advertising. For the customer, the discount amount is underestimated, or the official price of the advertising package is indicated at all. In addition, according to the chairman of the board of directors of the media buying agency IMHO A. Revazov, by agreement with the agency, the resource can artificially inflate the cost of advertising several times, after which the agency is given a discount from the inflated price list, which is hidden from the client. In most offline media, discounts are known, so the market is more or less transparent. In the network, so that the client does not run away from the agency directly to the resource, it is not customary to disclose their discounts from online advertising agencies.

Hiding the true cost of advertising when directly accessing resources is also quite common on the Internet. For example, the official cost of displaying a thousand banners in advertising networks is about $\$ 5$. In most cases, this cost can be reduced to 2-3 dollars per thousand impressions. In addition, there is a secondary market for banner impressions, where the cost of banners is quite scanty - something about 0.30.4 dollars per thousand. It is clear that such a spread of prices opens up wide opportunities for advertisers to manipulate reports. For example, you can issue invoices to the client for scrolling banners at the official cost (even at a discount), when in fact they were purchased on the secondary market.

Again, it uses customers ignorance of the subtleties of placing online advertising. There are several ways to place advertising materials on resources: statically-when the banner is placed on the site permanently for a certain period of time, and dynamically — when each banner display is paid for. The agency can purchase a static banner, and sell it to the client as a dynamic one, based on the cost per thousand impressions. For example, for $\$ 300$, you can buy a weekly static banner placement on a resource. Let's say the resource is gaining 20 thousand. daily visits, respectively, the advertiser's banner is displayed 20 thousand times. Selling an ad to a client on CP M terms at a price of $\$ 4$ per thousand impressions, the agency earns \$ $20 \times 4 \times 7=\$ 560$. That is, the agency will earn $\$ 260$ on this scheme. It would seem that not so much, however, as a rule, advertising is placed for more than one week and not on one resource, so as a result, a fairly solid amount can run up.

Many resources hide the statistics of visits, fearing that it will become known to competitors. This leaves almost no opportunity for the customer to monitor compliance with the terms of the advertising campaign on this resource. You need to 
install special software to track visits from this resource, or personally continuously monitor the progress of the campaign on the site. But even if the resource does not hide its statistics, there is no guarantee that the figures it shows in the report are true. In general, the statistics of traffic is one of the most painful places in the Russian Network, since it is high in network ratings, such as Rambler Top 100,

TopList, InfoArt 1000Stars, is in itself a very strong argument in a conversation with an advertiser. Therefore, very often resources tend to tweak the attendance counters of ratings in a big way, since the cheating technologies exist and are known. Ratings, in turn, try to fight this, but along with the methods of defense, the means of attack are also being improved. Thus, the site traffic announced to the advertiser is a fairly conditional figure. Moreover, different ratings will give out different traffic figures, and the number of visitors that the resource itself will receive will probably differ from the rating indicators.

Historically, many resources in the Russian Internet are owned by the same people. The individuals who make up the backbone of the existing Russian Network own most of the well-known brands. To some extent, this is an indicator of the small size of the Russian Internet market, since in developed markets, as a rule, such connections are quickly broken. Affiliated relationships between projects may or may not be advertised, but in any case they exist. This leads to the fact that the discount between related resources can significantly exceed the discount issued outwards for individual clients or agencies. This may lead to the fact that the agency will try to place the client not on sites that are profitable for the client, but rather on related sites that are convenient for the agency, thereby earning more money and allowing affiliated structures to earn. It is clear that in words all the "relatives" disown such practices, declaring their readiness to serve the interests of the client until the last breath, but life shows that sometimes these promises are at odds with the actual state of affairs.

\subsection{Evaluating the effectiveness of an advertising campaign}

Monitoring an advertising campaign, analyzing its current results and evaluating their effectiveness is an integral stage of the entire advertising event planning process. Monitoring an advertising campaign is not a mandatory procedure, and in most cases, companies do not control the course of the process itself. Instead, managers analyze the sales performance of products before and during the entire advertising campaign and then make a conclusion about whether the advertising 


\section{METHODS AND ANALYTICAL TOOLS IN THE ADVERTISING

works or not. However, about half of all advertising campaigns do not lead to a clear (measurable) increase in sales.

If you do not follow the progress of the campaign, you can get a completely unexpected result when it is too late to take measures to correct the situation. Large firms monitor and evaluate their advertising campaigns even when all market factors indicate that advertising (incentive measures, a complex of intensive marketing communications) achieves sales goals.

The head of the advertising and marketing department, who is interested in success, should always be sure that the sale of products is provided by advertising, and not by other marketing factors, "mistakes" on the part of competitors or by the market itself (when general economic conditions change). In addition, he is interested in the possible impact of advertising on future sales.

Studies by various authors show that: at least $30 \%$ of the campaigns conducted in the United States had a negative effect, 20\%, at least, did not cause harm, 20\% had a small positive and $30 \%$ - a pronounced positive effect.

The data for European countries looks more modest: only $20 \%$ of campaigns had a pronounced positive effect. In principle, you should not expect 100\% advertising effectiveness at all. However, it is certainly necessary to predict or evaluate advertising costs and the resulting at least approximate result. Advertising spending in developed and civilized countries has long been a kind of tribute to the market, so as not to get lost among competitors.

Tracking an ad campaign requires a significant amount of financial resources. To begin with, you need to conduct a preliminary, or control, study, if it was not conducted when developing an advertising strategy. Then, during the campaign, one or more "waves" of studies are conducted, the results of which are compared with the control ones. Thus, the effectiveness of advertising is monitored. The cost of each interim study depends on the survey objectives, the size of the sample of respondents, the volume of the questionnaire or questionnaire, the probability of making a purchase, but in any case it remains quite high.

The process of monitoring an advertising campaign includes the measurement of the following successive stages of advertising communication:

1) contact with advertising;

2) the assimilation of information;

3) brand communication and positioning effects;

4) actions of target buyers;

5) sales volume or market share; 
6) profits.

A contact is usually called an opportunity to see or hear an advertising message at least once. This happened, that is, there was a contact when an ad is placed in one or more advertising distribution media that reach the target consumer. The degree of attention of consumers (whether they noticed or did not notice the ad) is usually evaluated at the next stage - the stage of assimilation of information.

It should be noted that the study of contacts is related to the measurement of the advertising power of the advertising medium, which can later be correlated with sales volumes or other advertising effects. There are many ways to measure the power of an ad: from an overall estimate of the cost of advertising, its placement in monetary terms, and the total number of ads needed to achieve the desired level of awareness(GRP), to a more accurate estimate of coverage with a minimum effective frequency of ad repeats (effective coverage).

The total number of ads placed over a given time period is also the gross estimate of ad contact. The CRP indicator does not take into account the number of contacts of individual consumers and is a simple calculation of the required number of contacts (often repeated) of the audience with advertising.

The GRP indicator can be compared with the total amount of advertising costs (GRP per monetary unit for a given time period). Their ratio shows whether financial resources are being spent effectively. The higher the value, the cheaper it is for each contact with the ad message.

GRP can also be directly linked to sales volumes. The result is a rough estimate of the effectiveness of the plan for using advertising resources. Rough for the reason that the indicator itself can be evaluated in different ways.

An important indicator in the study of contact with advertising is the effective coverage. This is the coverage of the target audience with the lowest effective frequency of advertising output and the most accurate assessment of contacts with advertising. To measure effective reach, the number of contacts with various advertising media is directly estimated (direct combination), or the frequency of ad recognition is measured. The minimum effective frequency is calculated for each advertising cycle, but the coverage at this minimum frequency is an indicator that can be recalculated for any period used for other control measurements.

If, at the end of the measurement, it turns out that effective coverage is not related to sales volumes, then something was not taken into account in the work of advertising communications. And we are not talking about the use of advertising tools, but about the advertising strategy or its creative execution. 
The concept of advertising effectiveness simultaneously contains such heterogeneous concepts as economic effect, psychological impact on representatives of target groups( psychological effect), social effect, which is expressed in a certain impact on the entire society as a whole (in particular, the influence on the formation of people's taste preferences, their views and concepts about various moral and material life values, etc.). On this basis, to compare and reconcile cash costs on promotions, profits, consumer preferences, prestige products and favorable public opinion about the activities of the organization-the advertiser is extremely complex, often nearly impossible task.

Therefore, despite the fact that the problems of determining the effectiveness of advertising has long been the leading specialists of many countries, this question refers to the most intractable, and today it is still pet any perfect formula or methodology for accurately measuring the effort and money with the end results.

It should be particularly noted that, contrary to popular belief, advertising is not the only "engine of trade", but only one of many. In the overall system of an extensive set of marketing activities, advertising is, as a rule, by no means the dominant element.

Practice shows that the most significant factors determining the increase or decrease in sales of any product are primarily the quality and consumer properties of the products themselves, their price, the general market situation, the actions of competitors, etc.That is why evaluating the effectiveness of advertising campaigns based on the results of sales of advertised products can give very serious errors.

Distinguish between economic efficiency and effectiveness of the psychological impact of media on human consciousness (drawing attention to advertising, commit to memory, etc.). Moreover, the psychological impact of the most productive if it leads potential customers to make a purchase. The economic effectiveness of advertising depends on its psychological impact.

The economic effectiveness of advertising is most often determined by measuring its impact on the development of trade turnover. The most accurate way to determine the effect of advertising is only possible if the increase in sales of the product occurs in cases of advertising new consumer goods.

At the same time, the purchase of an expensive durable product is usually preceded by mandatory deliberation. In this case, the effect of advertising may not appear immediately. First of all, the buyer learns about the release of the product, then he is interested in detailed information about its quality and properties. After 
that, the buyer can give preference to the advertised product and confirm the desire to purchase it, and only in the end he buys it.

To determine the extent to which advertising has affected the growth of sales, carefully analyze operational and accounting data. At the same time, it should be borne in mind that in addition to advertising, the sale of goods is affected by its quality and consumer properties, price, appearance, as well as the location of the trading enterprise, the level of customer service culture, the availability of similar products or products on sale. In this regard, when determining the effectiveness of advertising, it is necessary to determine which of the listed or other factors could influence the increase in turnover along with advertising. 


\section{SECTION 7.}

\section{ANALYSIS OF THE ECONOMIC EFFICIENCY OF AN ADVERTISING CAMPAIGN}

\subsection{Analysis of the relationship between the result obtained from advertising and the invested funds for its implementation over a certain period of time}

The effectiveness of advertising is the result obtained from the use of an advertising tool or the organization of an advertising campaign. Determining the effectiveness is a necessary condition for the proper planning and organization of the advertising activities of the company, the rational use of labor and material resources spent on advertising. The study of the effectiveness of advertising should be aimed at obtaining special information about the nature and relationship of factors that serve to achieve the goals of advertising with the lowest cost and maximum return, which will eliminate inactive advertising and determine the conditions for its optimal impact.

The economic efficiency of an advertising campaign is defined as the ratio between the result obtained from advertising and the invested funds for its implementation over a certain period of time. Here it is necessary to analyze the influence of the above-mentioned factors on the change in trade turnover. For example, studying the sales volume based on the seasonal factor for a certain period of time, comparing the results, studying the attitude of consumers to products/goods; identifying the price elasticity for your product when using sales promotion methods, etc.

Another way to determine economic efficiency. This is a method where several comparable markets are taken and, all other things being equal, they have different advertising effects. Next, the financial results are compared, the difference in which is compared with the difference in advertising budgets and make a conclusion about the contribution of advertising to the turnover.

It is quite difficult to immediately determine what effect the ad has had. This is possible only if the increase in sales occurs immediately after the impact of advertising. But this does not apply to such goods as expensive ones. They require that the consumer think about spending on them before buying. The difficulty is that in this case, the effect of advertising may not appear immediately. And it should be borne in mind that in addition to advertising, the volume of sales of goods (and this is 
most likely) is affected by its quality, price, as well as the location of the enterprise, the quality of customer service.

The additional sales volume under the influence of advertising can be determined by the formula (1):

$\mathrm{Od}=\mathrm{OS} * \mathrm{~N} * \mathrm{D} / 100(1)$

where Od - additional sales under the influence of advertising (in monetary units), OS - average daily sales up to a period of advertising, $\mathrm{P}$ - growth in the average daily sales for advertising and politiclly periods, in $\%, \mathrm{D}$ - number of days in the advertising and polarella periods.

In this case, the resulting effect of the advertising event is compared with the cost of its implementation. The results can be expressed in three ways: the effect of an advertising event is equal to the cost of its implementation; the effect of advertising is greater than the cost (profit); the effect is less than the cost (loss).

However, more precisely, the cost effectiveness of advertising characterizes its profitability - the ratio of profit to cost (2):

$$
\mathrm{P}=\mathrm{P} / \mathrm{W} * 100 \%(2)
$$

Where $\mathrm{P}$ is the profitability of advertising the product, $\%, \mathrm{P}$ is the profit received during advertising (in monetary units), $\mathrm{Z}$ is the cost of advertising this product.

The cost-effectiveness of advertising can also be determined by the method of targeted alternatives, when the planned and actual indicators are compared, estimated as a result of investing in an advertising campaign.

To assess the cost-effectiveness of advertising campaigns, the results of experiments can be used, the essence of which in most cases is as follows. Two or more local markets are selected, where the company operates for a certain period of time with different levels of advertising support (all other things being equal). The difference in trading results is correlated with the difference in the allocation of advertising, on the basis of which the conclusion about the economic effect is made.

In some cases, enterprises for various reasons can not use such an experiment, but they always have at their disposal expert and analytical methods for determining the economic effectiveness of advertising activities.

The allocation of the net effect of advertising, that is, the share of sales growth provided exclusively by advertising of the period for which advertising costs are taken into account, can be carried out by the method of expert assessments. To do this, the reasons for the change in sales volume are divided into the main and other reasons. The main one is the advertising activity of the company in the current 
period. Its share is determined in the range from one to zero by the residual method. The difference between the unit and the sum of the equity estimates of all other causes (the influence of previous advertising, the inertia of consumer behavior, seasonal fluctuations in demand, etc.) allows you to determine the share of the net effect of advertising.

Clearly, all the approaches considered have a certain value in analyzing the effectiveness of advertising activities. However, it is important to remember that in the end, the economic effectiveness of advertising directly depends on the degree of its psychological impact on the target audience (communication effectiveness).

It is necessary to choose the correct periods for accounting for the turnover before and after the advertising. It should not be allowed that in one of the periods there are holidays or any events that affect the growth of trade turnover. It is important to determine the duration of the pre-advertising and post-advertising periods. It is established that for most advertising media, the advertising and postadvertising period of accounting for trade turnover should be approximately twice as long as the pre-advertising period.

The economic effectiveness of advertising can also be judged by the economic result achieved from the use of an advertising medium or an advertising campaign. The economic result is determined by the ratio between the profit from the additional turnover obtained under the influence of advertising, and the cost of it.

When comparing indicators, it is necessary to make adjustments for: the impact of the previous advertising campaign; consumer behavior; repeated purchases based on previous feelings of the value of the product; seasonal fluctuations; inflationary expectations of consumers; methods of incentives, promotion, etc. The problem in assessing the effectiveness of advertising actions is and is urgent. The complexity of issues related to evaluating the effectiveness of advertising costs, as well as the need to implement an individual approach in each case, does not allow you to use accurate advice.

Since there are no such precedents on a massive scale in either Russian or Western advertising practices, the problem of advertising effectiveness is not completely solved. There is another way to evaluate-to oblige employees to record where the information about the company was received by those potential customers who applied to it. This is a fairly simple method that is easily applicable and allows you to evaluate the effectiveness of advertising at least in the first approximation. As an option-a questionnaire. 
However, it has drawbacks. This method does not allow us to record the impact of indirect and image advertising aimed at creating a favorable background that determines the choice in a competitive situation. In addition, the client is likely to remember the sources that are "on the ear".

Advertising policy is part of marketing, so you should apply marketing research. It is necessary to conduct a survey, both before the start of the campaign and after. On the other hand, you need to know your competitors. In such cases, the rating is determined. The rating of fame, the rating of trust, etc. Moreover, it is better to offer the respondent a list of competing enterprises at once. Let the client put them in their places.

Since the effect of advertising depends not only on the user, in order to determine the effectiveness of an advertising campaign, it makes sense to monitor the number of requests. Measure changes in the number of phone calls, store visitors, distributed price lists, etc.

The most expensive way, but also the most plausible way to get an answer to the question about the effectiveness of the RC is through research conducted by qualified marketing agencies. First of all, it is necessary to conduct a preliminary, or control, study, of course, if it was not conducted during the study of the advertising strategy. Then, during the campaign, one or more "waves" of studies are conducted, the results of which are compared with the "control"ones. They include surveys of the most typical representatives of the advertising audience, during which it turns out what exactly consumers know about the company, what they see the advantages and benefits of buying goods or using services, how they learned about the existence of the company, what image they have formed, how they understand advertising, etc. This is how the effectiveness of advertising is monitored.

The study of effectiveness with the help of specialized agencies is very professional and correct, but it does not mean that it is impossible to make approximate calculations on the effectiveness of an advertising campaign on your own. The progress of the process can be monitored at each stage, taking into account indirect signs of well-being or difficulties that have appeared.

\subsection{Analysis of the impact of advertising on the change in turnover}

The economic efficiency of an advertising campaign is determined by the ratio between the result obtained from advertising and the invested funds for its implementation over a certain period of time. However, it is with this calculation of the effectiveness of advertising that the question arises: "Where did the advertising 
work, and where is the influence of other factors?". Here we can advise you to analyze the impact of the above factors on the change in trade turnover. For example, the study of sales volume trends based on the seasonal factor for several periods (months, years); study of consumer sentiment in connection with inflationary expectations; identification of price elasticity for your product when using sales promotion methods, etc.

Another way to determine the economic efficiency (although less realistic for enterprises operating only in one market) can be the method when several comparable markets are taken and, all other things being equal, they have different advertising effects. Then the financial results are compared, the difference in which is compared with the difference in advertising budgets and make a conclusion about the contribution of advertising to the turnover of the company.

There is a way to evaluate the contribution of advertising based on comparing your own expenses with those of competitors and the corresponding sales volumes.

It is clear that financial indicators and advertising expenses are compared and, according to the above scheme, they look at the contribution of advertising to the dynamics of trade turnover.

The simplest method of determining the economic effectiveness of advertising is the method of comparing the turnover before and after the advertising event. According to this method, the economic efficiency of advertising is determined either by comparing the turnover for a certain period of the current year, when the product was exposed to advertising, with data for the same period last year, when the product was not advertised, or by comparing the daily turnover before and after the advertising event in the current time period.

The latter method is more acceptable in our conditions, given the constant increase in prices due to inflation, which makes it very difficult to compare data over long periods of time.

The final conclusions about the cost-effectiveness of advertising are obtained by comparing the additional profit received as a result of advertising with the costs associated with its implementation.

The study of the economic efficiency of advertising can also be carried out by comparing the turnover for the same period of time of two similar trading enterprises, in one of which an advertising event was held, and in the other not. The growth of turnover in a store where an advertising event is not held is due to the influence of those factors that act independently of advertising. The same factors affect the turnover in the store where the advertising event is held. 
Economic efficiency of advertising in this case is calculated by determining the relationship of the index of growth of the turnover of the store, where he held the promotion, to the growth of trade, where a promotion was not carried out. The final conclusion about the effectiveness of advertising is made as a result of an analysis of the cost of advertising and the additional profit received as a result of its implementation. The positive thing about this method is that with this calculation, we can exclude the influence of non-advertising factors on the increase in turnover and estimate the almost net economic effect of advertising.

To get more accurate data, you can perform a calculation using two methods at once, comparing the results to get more objective data.

It is necessary to choose the correct periods for accounting for the turnover before and after the advertising. It should not be allowed that in one of the periods there are holidays or any events that affect the growth of trade turnover. It is important to determine the duration of the pre-advertising and post-advertising periods. It is established that for most advertising media, the advertising and postadvertising period of accounting for trade turnover should be approximately twice as long as the pre-advertising period.

The economic effectiveness of advertising can also be judged by the economic result achieved from the use of an advertising medium or an advertising campaign. The economic result is determined by the ratio between the profit from the additional turnover obtained under the influence of advertising, and the cost of it.

In this case, the resulting effect of the advertising event is compared with the cost of its implementation. The results of this ratio can be expressed in three versions: the effect of promotional activities is equal to the cost of its implementation; the effect of promotional activities more cost for it (profit); the effect of promotional activities less costs (loss-making). In addition to the above indicators is calculated return on ad spend, the ratio of profits to expenses on advertising.

When comparing the indicators, it is necessary to make adjustments for: the impact of the previous advertising campaign; inertia of consumer behavior; repeated purchases based on previous feelings of the value of the product; seasonal fluctuations; inflationary expectations of consumers; other methods of promotion, etc. 
SECTION 8.

\section{QUANTITATIVE AND QUALITATIVE ASSESSMENTS OF THE EFFECTIVENESS OF ADVERTISING AND PR}

\subsection{Tracking an advertising campaign taking into account financial costs}

Monitoring an advertising campaign, analyzing its current results and evaluating their effectiveness is an integral stage of the entire advertising event planning process. Monitoring an advertising campaign is not a mandatory procedure, and in most cases, companies do not control the course of the process itself. Instead, managers analyze the sales performance of products before and during the entire advertising campaign and then make a conclusion about whether the advertising works or not. However, about half of all advertising campaigns do not lead to a clear (measurable) increase in sales. Moreover, 3 campaigns out of 10 ultimately cause a drop in brand sales. If you do not follow the progress of the campaign, you can get a completely unexpected result when it is too late to take measures to correct the situation.

Large firms monitor and evaluate their advertising campaigns even when all market factors indicate that advertising (incentive measures, a complex of intensive marketing communications) achieves sales goals. The head of the advertising and marketing department, who is interested in success, should always be sure that the sale of products is provided by advertising, and not by other marketing factors, "mistakes" on the part of competitors or by the market itself (when general economic conditions change). In addition, he is interested in the possible impact of advertising on future sales.

Tracking an ad campaign requires a significant amount of financial resources. To begin with, you need to conduct a preliminary, or control, study, if it was not conducted when developing an advertising strategy. Then, during the campaign, one or more "waves" of studies are conducted, the results of which are compared with the "control"ones. Thus, the effectiveness of advertising is monitored. The cost of each interim study depends on the survey objectives, the size of the sample of respondents, the volume of the questionnaire or questionnaire, the probability of making a purchase, but in any case it remains quite high.

The process of monitoring an advertising campaign includes the measurement of the following successive stages of advertising communication: 
1. Contact with advertising.

2. Assimilation of information.

3. The effects of communication and brand positioning.

4. Actions of target buyers.

5. Sales volume or market share.

6. Profits.

Research of the number of contacts with advertising. A contact is usually called an opportunity to see or hear an advertising message at least once. This happened, that is, there was a contact when an ad is placed in one or more advertising distribution media that reach the target consumer. The degree of attention of consumers (whether they noticed or did not notice the ad) is usually evaluated at the next stage - the stage of assimilation of information.

It should be noted that the study of contacts is related to the measurement of the advertising power of the advertising medium, which can later be correlated with sales volumes or other advertising effects. There are many ways to measure the power of an ad: from an overall estimate of the cost of advertising, its placement in monetary terms, and the total number of ads needed to achieve the desired level of awareness (GRP), to a more accurate estimate of coverage with a minimum effective frequency of ad repeats (effective coverage).

The cost of advertising. What amounts are spent on advertising communications? Is this question of interest to the company's management? The ratio of the level of costs and the level of increase in sales allows you to assess the situation in general terms. This assessment makes important financial sense, but at the same time it is also a way to identify the cause as well as the effect of the measures taken.

The total number of ads placed over a given time period is also the gross estimate of ad contact. The GRP indicator does not take into account the number of contacts of individual consumers and is a simple calculation of the required number of contacts (often repeated) of the audience with advertising.

The GRP indicator can be compared with the total amount of advertising costs (GRP per monetary unit for a given time period). Their ratio shows whether financial resources are being spent effectively. The higher the value, the cheaper it is for each contact with the ad message.

GRP can also be directly linked to sales volumes. The result is a rough estimate of the effectiveness of the plan for using advertising resources. Rough for the reason that the indicator itself can be evaluated in different ways. 


\section{METHODS AND ANALYTICAL TOOLS IN THE ADVERTISING AND PUBLIC RELATIONS INDUSTRY}

An important indicator in the study of contact with advertising is the effective coverage. This is the coverage of the target audience with the lowest effective frequency of advertising output and the most accurate assessment of contacts with advertising. To measure effective reach, the number of contacts with various advertising media is directly estimated (direct combination), or the frequency of ad recognition is measured. The minimum effective frequency is calculated for each advertising cycle, but the coverage at this minimum frequency is an indicator that can be recalculated for any period used for other control measurements.

If, at the end of the measurement, it turns out that effective coverage is not related to sales volumes, then something was not taken into account in the work of advertising communications. And we are not talking about the use of advertising tools, but about the advertising strategy or its creative execution.

\subsection{Preliminary or control study of the advertising strategy}

Information processing consists of analyzing the consumer's reactions to advertising: attention, memorization, emotional reactions, and acceptance. However, in the process of tracking an advertising campaign, attention and reaction are measured indirectly (since it is impossible to evaluate directly when the consumer contacts the ad). The measurements during the advertising campaign are similar to the measurements during the pre-testing process. In addition to assessing brand awareness, another important aspect is also subject to research: the actions of target customers. The study of the actions of target customers is especially important when conducting advertising events for the reason that it is their behavior in relation to our product after contact with advertising and behavior in the market in general that determines the course of advertising communications in the future and what effect of advertising can be expected in the end. If everything goes well during the advertising campaign, then the "internal" target audiences, loyal consumers of the brand and favorable non-permanent consumers should remain in their groups. At the same time, customers who belonged to the "external" target audience (non-permanent consumers of other brands, loyal consumers of other brands, or new users of this category of goods) should move to the category of "internal".

The recommended order of measurements (or simply the order of questions in the questionnaire) in the course of control surveys of consumers is given below: The need for a category (if such a goal is set). Recall of advertising by product category. Brand awareness: a) brand recall; b) brand recognition. The recall of the ad. Consumer actions (making a purchase). The intention to buy the brand. Attitude to 


\section{METHODS AND ANALYTICAL TOOLS IN THE ADVERTISING AND PUBLIC RELATIONS INDUSTRY}

the brand. Opinions about the benefits of the brand. Facilitating the purchase. The recognition of the ad. Characteristics of respondents (in terms of contacts with advertising media). The validity of such a sequence of measurements is illustrated by the example of mobile phones Mobile Phone (name changed).

The need for a category. The first question here is: "Are you going to buy a mobile phone?". The need is determined even before the specific brands of the product are named.

The recall of ads by product category is also at the top of the list - only the category name is needed for measurement. "What TV ads for mobile phones have you seen on TV?", "Have you ever seen a magazine or outdoor advertising of this product?". Respondents will certainly start mentioning specific names, so researchers should move on to more specific questions.

Measuring brand awareness may require evaluating brand recall or brand recognition (depending on the campaign goals). If both goals are present, the brand recall is evaluated first ("Which brands of mobile phones come to your mind first?"), and then recognition ("Which of these brands have you seen before?"). The first measurement is carried out without hints, the second-with hints in the form of showing respondents images of brands (or a list of their names).

Next, we investigate the recall of the ad ("What Mobile Phone TV commercials have you seen recently?"). The fact that in the previous dimension the respondent was shown a number of brands does not matter, because in this dimension he is already called a specific brand.

The next step is to measure the actions. Depending on the purpose of the ad, this may be a purchase ("What brand of phone have you recently purchased?") or related actions ("What mobile phone stores have you recently visited?"). The next question should be the question of what the chances were to buy a Mobile Phone, if the consumer would buy a phone for home, car, office, business negotiations or personal purposes. When assessing the attitude to the brand, it is important to mention: "How do you find mobile phones Mobile Phone - the best, functional or something else?» Then you need to find out your opinion about the brand of the phone in terms of design, price, service support, (if such a goal is set), etc.

The last measurement of information assimilation is the evaluation of advertising recognition ("Have you seen this video before and if so, how many times?"). This question should be the last one, because here the respondent is shown the ad itself, and this may affect further answers. At the end of the survey, the researcher has the task of determining the demographic variables of the respondent. 


\section{METHODS AND ANALYTICAL TOOLS IN THE ADVERTISING AND PUBLIC RELATIONS INDUSTRY}

But the most important information is the consumer's contacts with the advertising media: what TV programs they watch or what websites they visit. Research shows that people's media preferences change very slowly. Therefore, the measurement of the characteristics of target consumers can be attributed to a separate study and carried out every six months with one large sample.

\subsection{The dependence of advertising effectiveness on the survey objectives and the sample size of respondents. The dependence of the effectiveness of advertising on the measurement tools and the probability of making a purchase}

Tracking an ad campaign requires a significant amount of financial resources. To begin with, you need to conduct a preliminary, or control, study, if it was not conducted when developing an advertising strategy. Then, during the campaign, one or more "waves" of studies are conducted, the results of which are compared with the "control"ones. Thus, the effectiveness of advertising is monitored.

The cost of each interim study depends on the survey objectives, the size of the sample of respondents, the volume of the questionnaire or questionnaire, the probability of making a purchase, but in any case it remains quite high.

The process of monitoring an advertising campaign includes the measurement of the following successive stages of advertising communication: 1. contact with advertising; 2. assimilation of information; 3. effects of communication and brand positioning; 4. actions of target customers; 5 . sales volume or market share; 6 . profit.

The concept of advertising effectiveness simultaneously contains such heterogeneous concepts as economic effect, psychological impact on representatives of target groups( psychological effect), social effect, which is expressed in a certain impact on the entire society as a whole (in particular, the influence on the formation of people's taste preferences, their views and concepts of various moral and material life values, etc.). On this basis, to compare and reconcile cash costs on promotions, profits, consumer preferences, prestige products and favorable public opinion about the activities of the organization-the advertiser is extremely complex.

The profitability of advertising is the ratio of the received profit to the costs.

The effectiveness of the psychological impact of advertising means is characterized by the number of consumer coverage, the brightness and depth of the impression that these means leave in the memory of a person, the degree of attracting attention.

The effectiveness of the psychological impact of advertising on the consumer can be determined by observations, experiments, surveys: 
The observation method makes it possible to evaluate the psychological impact of advertising in natural conditions, in direct communication of the consumer with a certain advertising medium.

The experimental method is active. The study of the psychological impact of advertising here takes place in conditions artificially created by the experimenter. If the observation only records how the consumer relates, for example, to a certain display of goods, then the experimenter can rearrange the goods, and then observe the change in the reaction of buyers.

The survey method refers to active methods for determining the psychological impact of advertising. This method is time-consuming, but much more reliable than others, since it allows you to identify directly from the buyer his attitude not only to the advertising medium as a whole, but also to the individual components of this tool. Using the survey method, you can evaluate the impact of an advertising medium on customers and determine which elements of its design attract the most attention and are better remembered.

There are several main reasons for the low effectiveness of advertising:

1. The lack of specific goals and objectives of the advertising campaign.

2. The incompatibility of the goals and objectives of the advertising campaign with the goals of marketing activities, as well as corporate strategy.

3. Lack of information about the target consumer and the sources of information they receive (channels of access to the consumer).

4. No feedback from the consumer.

5. Segmentation errors.

6. Low qualification of employees responsible for advertising, as well as employees of advertising agencies.

7. Lack of systematization and consistency in the conduct of advertising campaigns.

The field of activity also leaves a certain imprint on the effectiveness of advertising as a method of promotion.

Usually, the goals of an advertising campaign are divided into quantitative and qualitative goals.

The qualitative goals usually include all the results that they want to achieve in this particular advertising campaign: an increase in turnover from $10 \%$ to $15 \%$; preparing consumers for the opening of a new store; reminding consumers about the availability of some product in the retail network, etc.Quantitative advertising goals characterize ways to achieve qualitative goals: to reach at least $40 \%$ of the target 
audience; to increase the level of active awareness to 25\%; optimization of the advertising budget - reducing its size by $10 \%$ due to the redistribution of information sources.

The economic efficiency of an advertising campaign is determined by the ratio between the result obtained from advertising and the invested funds for its implementation over a certain period of time.

Research and analysis in the field of PR includes media monitoring, media monitoring, press clipping, that is, all the important components of PR analysis and any serious marketing research.

Qualified monitoring is not just a review of the media, but a complex complex work. Media monitoring involves accurately determining the position of business in the mass consciousness or in the professional environment, the activity of the main competitors, existing trends and dependencies in the business, industrial, financial and political life of society.

The monitoring system includes: monitoring and analysis of media of information and entertainment content; monitoring of business media; monitoring of the banking press; monitoring of advertising, including on the Internet, specialized printed publications, etc.; monitoring of Internet publications; monitoring of central media; monitoring of regional media; monitoring of glossy magazines; monitoring of TV and radio; monitoring of foreign media.

The Media Monitoring Center monitors, extracts and systematizes the necessary information around the clock, conducts the necessary analytical work and provides its clients with its results in a convenient form for further use.

Monitoring is the tracking of publications on a specific topic in the media. The two main components of monitoring are the context (a list of keywords) and the media base (a list of sources).

Main types of media monitoring:

Monitoring your own activity in order to quickly respond to negative messages, as well as for future reporting on published publications; competitive monitoring in order to track the activity of competitors - as one of the components of marketing intelligence; review of market news in order to understand trends, changes in legislative regulation, etc.; archival/retrospective monitoring in order to summarize the results of the year; monitoring of advertising messages in order to compare the advertising budgets of the company and competitors and track the advertising activity of distributors. 


\section{METHODS AND ANALYTICAL TOOLS IN THE ADVERTISING AND PUBLIC RELATIONS INDUSTRY}

Media analysis is the most important part of any company's marketing activities. However, very often even large companies can not afford the content of analytical services and departments, especially if we are talking about complex and specific areas of marketing. Such as media analysis, media market analysis, PR activity analysis, and competitor information activity analysis. To solve these and other problems, it may be advisable to attract a specialized company that has sufficient experience in the field of PR analysis and market analysis.

The analytical Agency can provide services in the following areas: market analysis services; real estate market analysis; analysis of the market; analysis of the consumer market; the resource market analysis; a summary analysis of the markets of Russia, CIS countries and abroad; other types of analysis, marketing and PR studies.

Evaluation of PR activity is the ability of a marketer and a PR specialist to be aware of events and to see and change the situation in time.

Clipping is a report format for monitoring your own activity, as close as possible to a newspaper publication, including photos of company representatives, products, etc. It is useful if publications about the company are necessary for reporting on press activities. The obtained data can be easily used in the preparation of presentations, reports, etc.

Analysis of the PR activity of competitors is extremely popular when launching a new product or service, entering a new market, as well as when the company's share in the existing market falls. In all these cases, up-to-date, accurate and well-structured information about the PR strategy of competitors is one of the key factors that allow you to achieve success or solve problems.

Competitive analysis relies on the following key points: the Identification of targets and PR strategy of a competitor; Identification of strengths and weaknesses PR policy of a competitor; the Quality of management of a competitor, its corporate culture, Available resources competitor, its ability to raise additional resources in the area of information dissemination.

Analysis of the PR activity of competitors allows you to make a comparative analysis of market participants, identify their weaknesses and strengths, develop the most effective strategy and increase your competitiveness.

The reputation audit helps to determine the current attitude of the audience to the company/brand as accurately as possible and to place the right accents when changing the communication strategy. The reputation audit allows you to recreate the existing portrait of the company and see how it should change in the future. In 
addition, the reputation audit is a key indicator of the company's activities in the field of public relations.

Media audit/A survey of journalists. Qualified work with the media is one of the most important criteria for the success of any large company. That is why it is so important to assess the competence of the company's PR services responsible for this area of activity. Timely detection of problems in the work of the press service will save the company from incorrect coverage of its activities in the media and will help to make the necessary adjustments in a timely and cost-effective manner.

At the moment, there are two main ways to determine the effectiveness of the press services. The first is an audit of the press service's activities for a certain period, based on such criteria as:

- the number of events held; the number of releases prepared for the press; the range of contacts with the media (limited ways of interaction);

- the number and quality of information events; the quality of press releases and other media reports; the quality of the media database; the quality of the archive and reporting of the press service.

The second method is based on feedback from the primary audience of the press service, namely, journalists and other representatives of the mass media-editors, major bloggers. A qualified, accurate, correct survey of journalists will help to diagnose the problem and prevent its negative effect. 


\section{SECTION 9.}

\section{THE PROCESS OF CONTROLLING}

\section{AN ADVERTISING CAMPAIGN}

\subsection{Measuring contact with advertising}

The process of monitoring an advertising campaign involves measuring all six consecutive stages of advertising communication:

1) contact with advertising,

2) the assimilation of information,

3) brand communication and positioning effects,

4) actions of target buyers,

5) sales volume or market share and possibly brand equity,

6) profits. Below, we will look at the measurements that should be taken at each stage.

Contact as an opportunity to see (or hear) an advertising message. This means that contact occurs when an ad is placed in one or more advertising media that reach the target consumers. Whether consumers notice the ads or not depends on their attention, which is evaluated at the next stage, the stage of assimilation of information.

The study of contacts involves measuring the information power of an advertising medium, which can then be correlated with sales volumes or other advertising effects. There are many ways to measure the power of an advertising medium: from an overall estimate of the cost of advertising in monetary terms and the total number of ads needed to achieve the desired level of awareness, to a more accurate estimate of coverage with a minimum effective frequency of ad repeats (effective coverage).

In any case, media dimensions are calculated for a certain period of time. This can be a week, a month, or a longer period, depending on how often you need to measure sales or other intermediate effects.

The cost of advertising. How much money is spent on advertising — that's what the top management of the company is interested in. The ratio of the level of costs and the level of increase in sales allows you to assess the situation in general terms. This estimate has an important financial meaning, but at the same time it is a general cause-and-effect indicator. 


\section{METHODS AND ANALYTICAL TOOLS IN THE ADVERTISING AND PUBLIC RELATIONS INDUSTRY}

Total number of ads (GRP). The number of ads placed over a certain period of time is also the gross estimate of the ad contact. We have already mentioned that the GRP indicator does not take into account the number of contacts of individual consumers and is a simple calculation of the required number of contacts (often repeated) of the audience with advertising.

First, the GRP indicator can be compared with the total amount of advertising costs (GRP per monetary unit for a given period). Their ratio shows whether the money is being spent effectively. The higher the value, the cheaper it is for each contact with the ad message.

Second, GRP can also be directly linked to sales volumes. We will get a rough estimate of the effectiveness of the advertising plan. Rough-because the indicator itself can be evaluated in different ways, based on different coverage schemes and levels of frequency of contacts with advertising.

To measure effective coverage, you either need to directly estimate the number of contacts with different advertising media (direct combination) by including this question in the corresponding questionnaires, or, much faster and more reliable, estimate the frequency of ad recognition (The minimum effective frequency is calculated for each advertising cycle $(\mathrm{MECH} / \mathrm{c})$, but the coverage at this $\mathrm{MECH}$ (effective coverage) is an indicator that can be recalculated for any period that was used for other control measurements. This can be, say, 4 weeks, rather than 3 weeks, which make up the advertising cycle.

If it turns out that effective coverage (the level of coverage of the target audience at the minimum effective frequency) is not related to sales volumes, then something has been done wrong. The point, most likely, is not in terms of the use of advertising tools, but in the advertising strategy, or in its creative execution. Fortunately, tracking an ad campaign, since it consistently covers all stages of advertising communication, usually allows you to detect the source of the problem.

\subsection{Studying the effects of brand communication and positioning}

The model of the effectiveness of marketing communications, proposed in the work of J. R. R. Tolkien. Rossiter and L. Percy includes 6 consecutive stages of achieving effectiveness, each of which achieves a certain effect of communication:

- the contact the user with the message;

- processing of message information;

effects of communication and positioning of the brand;

- actions of target customers; 
- increase in sales or market share, creation of brand capital;

- making a profit.

The first four effects (contact, information processing, brand communication and positioning effects, and target customer actions) are called buyer reaction stages.

The phrase "advertising effectiveness" has many meanings due to the fact that each of the words of this phrase can be understood in different ways. The word "efficiency", as we have already emphasized, can be used in the sense of" commercial efficiency "and in the sense of "communicative efficiency". Since advertising is a communicative component of the marketing mix, it is correct to evaluate the communicative effectiveness of advertising. The word "advertising" can also be used in different meanings: advertising activity, advertising campaign, advertising message. Each of these objects is associated with specific performance calculation models.

The communication component of an advertising campaign is usually modeled based on a five-level model of communication effects.

Communication effects are relatively stable judgments and associations associated with a given brand. With their help, a clear positioning of the brand in the market is created and the consumer's predisposition to purchase this brand is formed. Communication effects can be the result of a successful advertising campaign (as well as the result of other types of marketing communications or a combination of them). J. Rossiter and L. Percy identify 5 communication effects:

- the need for a product category;

- brand awareness;

- relationship to the brand;

- the intention to buy a product of a certain brand;

- facilitate the purchase.

A very special area of research is the evaluation of the effectiveness of advertising messages. Let's look at this problem in more detail.

Criteria for evaluating the communicative effectiveness of an advertising message

Every firm that invests money in advertising has the right to know whether and to what extent its advertising activities contribute to the success of the firm. Many believe that any advertising contributes to the company's popularity, increases confidence in its products and services, forms an attractive image of the company, helping it to stand out among competitors, maintains the attachment to the company of its customers and employees, improves the opinion of the company among the 
general population, as well as business partners. However, advertising is different from advertising. In the advertising business, there is a situation when a video or poster that is interesting in artistic terms and has been awarded at a prestigious festival does not bring the desired success to the advertiser. Not all advertisers know that their ads may not be noticed at all by those they are aimed at. Few people understand that sometimes advertising can even damage the company.

In the history of advertising, there are cases of failure of entire advertising campaigns due to unprofessionally created advertising. So, in the famous book by V. Packard "Hidden Admonishers", an example of a failed advertising campaign for fast instant coffee at a time when it first appeared on the American market is given. It would seem that customers should have appreciated the main benefit that was presented in advertising - saving time and ease of preparation. However, the reaction to this product was sharply negative for two main reasons.

First, instant coffee was perceived as coffee that had undergone additional processing and, therefore, lost some of its real flavor.

Secondly, the preparation of coffee by a housewife was traditionally perceived as a sign of the hostess's attention to her relatives or guests.

Since the advertisers focused on the simplicity of preparation and saving time, instant coffee was perceived as a poor substitute for real coffee, prepared by a careless and lazy hostess. These undesirable associations became the subject of attention of advertisers only after the start of the advertising campaign, although they could partially be anticipated and identified at the stage of market research or at the stage of testing the finished advertising before it was released to the market. Moreover, advertising, thanks to the inept choice of the main statement, only reinforced the undesirable associations that the product itself had. In the following advertising campaigns, we had to fight against the persistent prejudice against this coffee. It was necessary to create a new, positive system of associations.

This is a case of advertising failure, which quickly and dramatically affected the sale of the product. Such failures due to inattention to the peculiarities of a person's subjective perception of goods, services and the very image of the company are not uncommon today (although, as a rule, they are a trade secret). However, more often the advertiser simply does not suspect that his advertising does not work for him, that its effect does not justify the invested funds at all.

A company that cares about its reputation should know how its advertising will work even before placing ads in the media, in order to be able to quickly correct its undesirable effect and strengthen the positive one. 
Long-term research on communication effectiveness aims to find answers to the following questions:

- Why do people notice one ad faster than another in the general information flow?

- Why is one advertising message easier and easier to understand than another?

- Why is one ad read (listened to)?) until the end, and the other one is skipped?

- Why is one ad better remembered than another?

- Why is one advertising information credible, and the other is not?

- Why does one ad improve the attitude to the company (or its products), and the other does not change it or even worsen it?

- Why does one ad encourage contact with the company (to purchase its products, to use its services), and the other does not affect the intentions of the person?

The communicative effectiveness of the message consists of the following set of factors: the impact of the message on the change of knowledge about the company, its products and services (cognitive level), on the formation of a positive attitude towards it (affective level), as well as on the formation of intentions to contact the company, to purchase its goods (conative level). The main approaches to evaluating the effectiveness of advertising messages are discussed in a number of monographs on advertising (Reeves, 1983; Deyan, 1993; Bove, Arens, 1995; Baldwin, 1989; The Politz papers, 1990, etc.).

These changes can be identified through special surveys and tests that show: at the cognitive level:

- changes in the degree of brand actualization in the minds of representatives of the target audience;

- changes in the level of brand awareness;

on the affective level:

- changes in the attractiveness of the brand image;

- presence/absence of undesirable associations;

at the conative level:

- changes in the level of trust in the brand;

- changes in the level of positive interest (that is, the interest necessary to lead to contact with the company or to the purchase of a brand).

Testing of the communication effectiveness of an advertising message is usually carried out at two stages: before its release to the market and after its release (during the advertising campaign and following its results). At the first stage, 
preliminary assessments of the quality of advertising and its ability to perform the tasks are given. At the same time, several variants of the same ad are often tested in order to choose the most successful one among them. Based on the results of the first stage of testing, you can predict the effectiveness of the impact of advertising on the consumer, identify its strengths and weaknesses, and, if necessary, adjust the advertising message. In the second stage, when the advertising message is already released to the market and took some time enough to explore is the target audience, testing aims to bring intermediate or final result.

The main criteria of communicative effectiveness. Regardless of whether the company will conduct testing, it is important to be able to predict (of course, with a certain degree of probability) the communicative effectiveness of advertising materials, to give them an expert assessment. As already emphasized above, there is no universal criterion for determining the effectiveness of advertising, so a whole set of criteria is used. The expert assessment can be given taking into account the following main criteria of communicative effectiveness:

- recognizability (identifiability) Messages;

- memorability of the message;

- the attractive power of the message;

- agitation power of the message.

For each of these criteria, specific techniques can be specified that increase or decrease the effectiveness of the advertising message.

\section{RECOGNIZABILITY (IDENTIFIABILITY) ADS}

Recognizability is a property of an advertising message that allows you to quickly relate it to a specific company (or brand), as well as to perceive its main subject matter during a cursory viewing. Recognizability is a very important indicator, since it fundamentally affects the number of real (and not expected) contacts of the consumer with the advertising message. High recognizability affects the degree of actualization of the company (or brand) in the minds of people belonging to the target audience: the more often a person encounters the advertising of the company (brand), the easier it pops up in his mind.

Recognition of identification marks

Recognizability is the criterion by which identification marks are evaluated first of all: a trademark, a logo, a company name and a brand, etc. Identification marks that meet two conditions are rated higher in this parameter:

1) they take less time to recognize;

2) they are perceived in a wider spatial range. 
The first condition is especially important at the initial stage of the company's existence on the market, when very few people know about it and its identification marks have not yet become easily recognizable. Keep in mind that it takes much longer to recognize an unfamiliar name, logo, or trademark than it does to perform the same operation with a familiar one.

Typical errors that reduce the recognition of identification marks:

a) the use of a hard-to-read font in the name;

b) exposing it on a non-contrasting, non-uniform or moving background and other visual techniques that make it difficult to read;

c) the insufficient duration of exposure in television advertising of the brand or company name, logo or trademark (this is compounded by the fact that in our market there are many long foreign-language names of brands and companies, which are also difficult to read in Latin graphics);

d) visual demonstration of the name without pronouncing the name in the video and, conversely, pronouncing the name without its visual demonstration;

e) lack of clarity in the pronunciation of the name by the announcer or character (sometimes the name sounds only in the song or is pronounced in a difficult rhythm for perception).

Here are some examples.

In the advertising of the company "PRESENT LUX" in the newspaper "EXTRA M", the name of the company is placed directly on the image of office furniture, which significantly complicates its reading.

Of the three bank names "INTERPROGRESSBANK", "TRANSCAPITALBANK" and "UNICOMBANK" at the initial stage, the latter wins primarily due to its shorter length and greater euphony. In addition, the bank's logo was successfully chosen, which includes the bank's name in its full form, divided into two parts ("UNICOM "and" BANK"), thanks to the change of typefaces and background color (gray in the first part, black in the second). Perhaps it would be better to use a black background for the first part, and a gray background for the second, since it is the first part of this name ("UNIQUE") that has a great meaningdistinguishing function. In print and on television, different advertisements of this bank appear, which differ markedly in the level of recognition of the logo. In most cases, the logo stands out in contrast against the general background. However, in some ads in Financial News, the message is placed on a gray background, as a result, the first part of the logo simply sinks into it, while the second part still stands out in contrast. At the same time, the unity of the composition and font design of different 
newspaper ads of this bank somewhat smooths out the lack of ads with a gray background, making them recognizable in the general flow.

This technique of creating a serial message-using a single system of font, image and composition design of different ads of the same company-helps recipients to identify them as ads of this company, without reading them yet. This approach to the design of their promotional materials using, for example, also "MEZHKOMBANK". However, this technique is not without its drawback. In a series of equally designed, but different in content ads, it is more difficult to recognize new information (a change in the advertised service or the advertised product).

The second condition affects both the number of real contacts with the advertising message and the duration of this contact. Here it is important to take into account the angle of view, as well as at what distance the company's identification mark becomes distinguishable. Although this factor is applicable to any form of advertising, it is particularly important in outdoor advertising.

Recognizability of the message as a whole. According to the recognition criterion, not only the identification marks are evaluated, but also the ad as a whole.

Let's take as an example the print advertising of the Scandinavian airlines SAS. In newspapers, several versions of the ad are used, differing mainly in the illustration. In one version, an image of an airplane is used, in the other-a large image of a compass, resembling a watch face. The first version of the ad is significantly better than the second one in terms of recognizability, since information about the company's field of activity is transmitted quite clearly with the help of an illustration. The second version of the ad first makes it assume that the watch is being advertised; The title of the message ("Purely Scandinavian quality") and the first phrase of the subtitle ("Eurobonus SAS") also do not provide clarity. Only after getting to the second phrase of the subtitle ("The best aviation program"), the reader can understand that we are not talking about hours, but about aviation flights.

It should be borne in mind that informative headings, subheadings and illustrations significantly facilitate the recognition of the message.

Advertisers should also know an interesting feature of human perception, due to the fact that advertising is often viewed inattentively. If the company (or brand) is advertising) A borrows the style of another, more well-known company (or brand) B, then consumers can perceive such advertising as advertising brand $\mathrm{B}$. 
Methods for testing the recognizability of ads. To more accurately determine the level of recognition of the message, you can conduct a survey in which potential customers of the company or potential consumers are asked the following questions:

Is it clear which company we are talking about? (Is it clear which brand or service is advertised?) Is it

clear what the scope of the firm is? (Is it clear what this product is?) Is

it clear what the ad is about, is it easy to understand?

Is the meaning of the ad clear?

To determine the speed of recognition of identification marks and advertising in general, a tachytoscope is used - a special device that allows the participants of the experiment to present an ad for different time intervals, up to fractions of a second.

\section{AD MEMORABILITY}

The memorability of an ad is a property of a message that allows it to be held in memory for a long time. Memorability is one of the main criteria for communication effectiveness, which can be used to indirectly judge the commercial effectiveness of advertising. The use of this criterion is based on the hypothesis formulated by the classics of advertising R. Reeves and A. Politz and shared by many modern advertisers: memorability leads to preference. A. Politz ("The Politz papers", 1990) formulated this feature of human behavior in the form of the "familiar brand"principle. He found that increasing knowledge about a brand (or firm) increases trust in it and increases its quality rank in the perception of consumers. Even a simple knowledge of the name of a brand (or company) increases the credibility of it in comparison with a completely unfamiliar brand (or company).

How to increase the memorability of ads. It is important for advertisers to know which properties of the advertising message increase the memorability of the brand and the main advertising statement. Memorability is increased by three main techniques: informational repetitions within an advertising message, unusual information or advertising images, and the integrity of advertising. Knowing these properties helps you predict the memorability of ads without prior testing, so let's look at them in a little more detail.

The principle of information repetition is one of the leading principles of any learning theory. In order for the name of the company (or brand) and the main statement to be better fixed in the mind of the potential buyer, advertisers often use in-text repetitions. It is considered useful to repeat the name in different parts of the text; and the main statement can be repeated in different ways in the text (usually at 


\section{METHODS AND ANALYTICAL TOOLS IN THE ADVERTISING AND PUBLIC RELATIONS INDUSTRY}

the beginning and at the end). Increases the memorization of information and a clear visual image that supports the main statement about the product.

The unusual nature of the information also increases its memorability, provided that the unusual information is specifically emphasized in the message. Otherwise, it may be overlooked or distorted by the consumer.

According to the theory of cognitive dissonance, the new information that a person perceives may conflict with the existing knowledge. This situation creates a mismatch of new and old knowledge, a cognitive dissonance from which a person consciously or subconsciously seeks to find a way out. There are three standard ways to overcome the state of dissonance:

a) ignore the new information;

b) reject new information; c) combine new information with old knowledge.

The first way: a person may not perceive the new information at all. This process usually occurs at the subconscious level; a person simply does not notice information that contradicts his knowledge, or incorrectly perceives this information, distorting it so that it better meets his expectations (the alignment effect). This often happens when most of the message is consistent with expectations and old knowledge, and only a small part contradicts them.

The second way: a person may not believe the new information and on this basis deliberately reject it. As a rule, the reason for this in advertising can be too strong statements and promises and not enough convincing or not enough detailed arguments.

The third way: a person can rearrange their old knowledge in such a way that the new information fits harmoniously into them. This is exactly what advertisers want to achieve by providing unexpected information. However, it should be borne in mind that just the last way out of the conflict requires a lot of cognitive effort from a person, and therefore he often chooses the easier way. Therefore, the task of the advertiser is to do everything so that unusual information can not be overlooked, it is difficult to misunderstand, and try to convince the consumer that this is not an exaggeration and not a deception.

\subsection{Analysis of the actions of target buyers}

Consumer analysis is an attempt to recognize their needs and requests, to understand the reactions to certain actions of the company. The structure of consumer needs, requests and preferences is, first, a set of internal (goals, age, personal qualities, social status) and external (place of work, environment, marketing of 


\section{METHODS AND ANALYTICAL TOOLS IN THE ADVERTISING AND PUBLIC RELATIONS INDUSTRY}

enterprises) factors that determine the consumer's behavior in the market; second, individual elements of this behavior (motives, incentives, feelings, perception of the consumer), according to which he makes a choice of this product from many others.

The goal is to identify the motivating factors that guide consumers when choosing products and identify target segments.

When researching consumers, you need to answer the following questions::

1. What are the unmet needs associated with this product, there are buyers?

2. Can your company meet these needs?

3. Who is currently the buyer of your product (the client of the company)?

4. To which marketing factors (price, advertising, image, service) are buyers most sensitive?

5. How is the purchase decision-making process carried out and who is involved in it?

6. How many segments can be identified in this market?

7. Which of the segments can be targeted for your company?

Research of your company's partners. Partners are all firms or individuals who are interested in achieving the firm's goals. These include:

- suppliers;

- intermediaries;

- contact audiences (banks, insurance companies, advertising agencies, etc.).

The study of suppliers evaluates the quality, prices of suppliers, their distance, reputation in the industry, the experience of existing transactions, and the possibility of influencing the policy of suppliers.

When studying intermediaries, it is necessary to assess the experience of selling such products, the location of intermediaries (especially if they are retailers), the degree of compliance with the qualifications of sales agents or sellers (if required).

The research of the contact audience is conducted in order to explore the possibilities of establishing business relationships in the future. For example, we study the bank loan rate of various banks, the conditions and types of insurance in insurance companies, the creative potential of advertising agencies, etc.

Development of the company's product policy. When developing a product policy, you should:

- conduct a three-level analysis of the product to improve its capabilities as a product;

- make decisions regarding the range of products (services); 


\section{METHODS AND ANALYTICAL TOOLS IN THE ADVERTISING AND PUBLIC RELATIONS INDUSTRY}

- make decisions about the name of the product, its brand name, design and packaging (if your company provides services, then we are talking about the name of the company, the design of the premises and equipment);

- develop a corporate identity;

- make decisions regarding the development of new products;

- make decisions regarding pre-sales and after-sales service;

- develop a product position.

An important role in the product policy is played by the management of the assortment (nomenclature), the main purpose of which is to optimize it. In the process of optimization, management is focused on the main characteristics of the assortment (nomenclature): breadth, richness, depth, harmony.

The breadth of the nomenclature is the totality of all product groups. For example, if a company sells (produces) household chemicals, clothing, and shoes, then the latitude is three.

Saturation is the total quantity of all goods produced (sold).

The depth of the nomenclature is the totality of all the variants of each individual product within one assortment group. For example, if the washing powder "MYTH" is offered in three different packages (150, 450 and $900 \mathrm{~g}$ ) and with two flavors (normal and "frosty freshness"), then the depth of its offer is six.

The harmony of the nomenclature is the degree of proximity between the products of different product groups in terms of their end use, requirements for the organization of production, distribution channels. Thus, the product groups of Procter $\&$ Gamble are harmonious, since they are all sold through the same distribution channels, but at the same time they are not harmonious in the nature of their use (Pringles chips, Tide washing powder, Camay soap, Fairy dish washing liquid, Head \& Sholders hair shampoo, etc.).

To assess the correctness of actions when developing a product policy, game teams should test themselves by answering the following questions.

1. What advantages does your product (service) give to customers?

2. Can your products successfully compete with the products of your competitors?

3. Is it possible for competitors to copy your products?

Positioning is the development of actions aimed at creating a separate favorable position of the product in the minds of the target group of consumers.

Product positioning can be carried out relative to consumers and relative to competitors. In consumer positioning, the main attention is paid to emphasizing the 
consumer advantages and advantages of the product. A necessary element of a strong position in this case is an advertising slogan (slogan, motto).

There are several approaches to determining a strong position for the consumer:

- the position of the product can be determined by its specific property, or reliable, distinctive quality ("From Paris to Nakhodka - "Omsa" best tights!", "Maggi" - add a twist!»);

- the position of the product can be determined by the benefit or the solution to the problem ("No time to get sick? "Bittner". Just "Bittner", "Knorr" - delicious and fast!");

- the position of the product can be determined by the joy, life affirmation or the promise of good that will come with the product ("Roventa" - joy in our home!", "Mulinex" - we must live playfully!").

Competitive positioning is information about the advantages of a product in comparison with competing ones. As a rule, competitive positioning is used after the approval of goods in the market and the aggravation of competition.

Development of the company's pricing policy. Price is the only element of the marketing mix that generates revenue, while the rest of its elements increase the costs of the enterprise. In addition, price is one of the most flexible, easily changeable elements of it, in contrast to the product characteristics and obligations associated with distribution channels. At the same time, pricing policy is the main problem of marketing.

Pricing policy, as a component of the marketing mix, should be developed taking into account the following factors.

- the objectives of the enterprise;

- external and internal factors affecting the pricing policy of the company;

- the degree of price elasticity of demand;

- production, sales and distribution costs;

- the perceived and real value of the product;

- policy of the competitors.

The development of the pricing policy includes:

- setting the initial price for the product;

- timely changes in prices in order to bring them in line with changing market conditions, the company's capabilities, its strategic goals and objectives (making decisions on the use of price strategies).

When developing the pricing policy of an enterprise, it is necessary to: 
- evaluate the impact of all of the above factors;

- choose and justify the pricing method;

- make a decision on price discounts;

- describe the actions of the company in the event of changes in the prices of competitors ' products.

Development of the company's sales policy. The main tasks in the development of sales policy are:

- selection of the distribution channel;

- making a decision on the sales strategy.

When developing a sales policy, game teams need to decide on the method of sales - through intermediaries, without them, or use both methods at the same time.

When choosing the method of distribution of goods through intermediaries, you should determine the number of levels in each distribution channel. In this case, it should be remembered that distribution channels with a large number of levels are suitable for inexpensive standard goods (canned food, chewing gum, clothing, shoes, stationery, etc.). Short channels are used for perishable, heavy and bulky goods and for goods of high technological complexity. As a rule, the fewer levels in a channel, the easier it is to control it.

Next, the game team needs to determine how many intermediaries will be needed to ensure the level of market coverage needed to penetrate it. You can use one of the following sales strategies:

- intensive sales strategy;

- selective marketing strategy;

strategy is the exclusive marketing and distribution.

To assess the correctness of the chosen strategy and distribution channels, game teams should test themselves by answering the following questions:

- what will be your sales costs in each channel?

- what are the trade margins in each channel?

- what part of advertising does the sales system take on?

- what kind of support can wholesale and retail traders expect from you? The most typical ways to encourage trading partners:

- grocery (the intermediary is given the opportunity to sell unique, particularly attractive products for buyers);

- logistics (reduction of delivery time, prompt execution of orders);

- security clause (on the return of unsold goods at the purchase price, consignment agreement); 
- price (provision of discounts, preparation of stable price lists);

- financial support (discounts on the loan, extension of the loan term, discounts for cash payments);

- facilitating the sales process (staff training, product promotion programs, repairs, etc.).

If the game team has chosen a retail company to develop a marketing plan, it is necessary to make decisions about the qualifications, appearance and personal qualities of the store's employees.

Development of communication policy. Communication policy is a set of ways to promote a product on the market. The main ways of promotion are:

1. Advertising activities. It is understood as any presentation and promotion of a product that is not addressed to a specific consumer.

2. Sales promotion. These are short-term incentives (discounts, gifts, souvenirs) for consumers that interest them in making a purchase of a particular product or service.

3. Public relations events. Activities aimed at forming a favorable public opinion about the company's activities or its products.

4. Personal sales. Provide for direct contact with one or more potential buyers by organizing product presentations in order to receive orders (or sell the product).

When developing a communication policy, the game team must decide on the structure of the incentive package. At the same time, it should be remembered that the comparative significance of the main methods of product promotion in the consumer and business markets is different.

All sales promotion activities, depending on the degree of their effectiveness in the consumer and business markets, can be ranked as follows:

- for the consumer market-advertising; sales promotion; personal sales; public relations events;

- for the business market-personal sales; sales promotion; advertising; public relations events. 


\section{CONCLUSION}

The analysis of PR activities is of the utmost importance. This is due to the importance of tracking the process of PR activity from its beginning, that is, at the stage of collecting information and forecasting, and until its end-evaluating the effectiveness. Research methods in PR are used both in the development of complex PR campaigns and current PR activities, to identify the stage of development of the company, brand awareness, prevention of problems or solutions to existing ones, etc.

Research in public relations is divided into qualitative and quantitative indicators, all studies have their own individual characteristics, but they are united by the main requirements. First, all research in PR should be aimed at a specific segment - the target audience. Secondly, the choice of the research method should provide specific information that corresponds to the problem being studied. The results of the study should be as accurate and objective as possible. All studies can be quantitative or qualitative. Sometimes there are methods of qualitative and quantitative properties, meaning the possibility of using methods of psychosemantic evaluation of the properties and qualities of the product in advertising.

Quantitative methods include sociological and interactive surveys, while qualitative methods include expert surveys, focus groups, and desk research (analysis of working documents, mass media, the Internet, and marketing research).

Sometimes, if necessary, media research (content research, opinions, facts, monitoring) and media statistical research (ratings, content analysis, shares of the information field) are carried out.

Since advertising and PR activities imply the need for a socio-psychological study of various market phenomena, in such cases it is appropriate to use, if necessary, such special research methods as the analysis of awards and ratings (surveys of the target audience about brands and preferences, some economic indicators), as well as the analysis of internal audit indicators (communication audit, SWOT analysis).

In any case, when it comes to the need for scientific justification of the results obtained in the field of advertising or PR activities, the use of analysis methods allows you to get a concrete idea of the meaning, essence and direction of media planning. 


\section{REFERENCES}

1. Berezin I. S. Marketing analysis. Market. The firm. Product. Promotion/I. S. Berezin. - 3rd ed., reprint. and additional-M.: Vershina, 2007. - 480 p.: ill., tab. ISBN 978-5-9626-0335-3.

2. Bolshakov T.B., Irtegov D.V. Operational systems. The materials of the site http://www. citforum.ru /operating_systems/ois/introd. shtml.

3. Vasiliev G. A., Zabegalin D. A. Advertising on the Internet. - M., 2008

4. Kotler F. Marketing management; translated from English by S. Zhiltsov [et al.]. - 12th ed. - St. Petersburg: Peter, 2010. - 816 p.: ill. - (Series "Classic foreign textbook"). - ISBN 978-5-469-00989-4.

5. Kutlaliev A., Popov A. The effectiveness of advertising. - M.: Eksmo, 2005. - 416 p. - (Professional publications for business). - ISBN 5-699-10796-7.

6. Methods and tools for developing the user interface: the current state, Kleshev A. S., Gribova V. V., 2001. The materials of the site http://www. swsys. EN/index. php? page $=$ article\&id $=765$.

7. Romat E. V. Advertising. History. Theory. Practice. 2002

8. https://studfiles.net/preview/5388752/page:6/

9. https://www.marketing.spb.ru/mr/media/online_adv.htm

10. http://powerbranding.ru/mediastrategiya/advertising-r..

11. https://studme.org/1359042111542/marketing/otsenka_ef..

12. https://www.rae.ru/forum2012/327/1402

13. https://www.osp.ru/os/2006/09/3776464

14.https://studbooks.net/840344/marketing/banner_osnovnoy_reklamnyy_nosit el_internet

15. https://marketing.wikireading.ru/1818

16. https://reklamaplanet.ru/marketing/bannernaya-reklama-v-internete

17. https://lektsii.org/13-54906.html 
УЧЕБНОЕ ИЗДАНИЕ

Мулина Наталья Алексеевна

Чвякин Владимир Алексеевич

\section{METHODS AND ANALYTICAL TOOLS IN THE ADVERTISING AND PUBLIC RELATIONS INDUSTRY}

\section{Textbook}

Формат 60х84 1/16. Усл. печ. л. 5,75.

МЦНП «Новая наука»

Под общей редакцией Н. Г. Кобусь, кандидата психологических наук

185002, г. Петрозаводск

ул. С. Ковалевской д.16Б помещ. 35

office@sciencen.org

www.sciencen.org

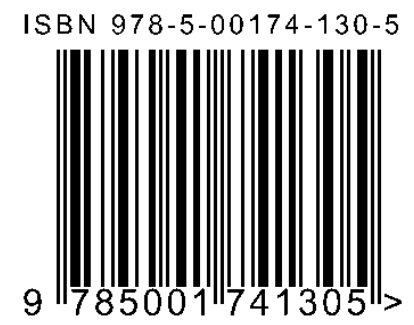

